\title{
PETROGRAFIA E GEOQUÍMICA DO GRANODIORITO RIO MARIA DA REGIÃO DE BANNACH E COMPARAÇÕES COM AS DEMAIS OCORRÊNCIAS NO TERRENO GRANITO-GREENSTONE DE RIO MARIA - PARÁ
}

\author{
MARCELO AUGUSTO DE OLIVEIRA ${ }^{1,3}$, ROBERTTO DALL'AGNOL $^{1,2} \&$ \\ FERNANDO JACQUES ALTHOFF ${ }^{1,4}$
}

\begin{abstract}
Resumo O Granodiorito Rio Maria (GDrm) ocorre em diversos domínios do Terreno Granito-Greenstone de Rio Maria (TGGRM), no sudeste do Cráton Amazônico. As ocorrências do GDrm, a leste da cidade de Bannach (GDrm $\left.{ }_{\mathrm{B}}\right)$, situam-se imediatamente a oeste de sua área tipo. Na área estudada, o Granodiorito Rio Maria é intrusivo nas seqüências supracrustais do Supergrupo Andorinhas e admite-se que possua idade similar a das associações de tonalitos-trondhjemitos arqueanos (TTG). Ele é intrudido por leucogranitos correlacionados aos granitos Xinguara e Mata Surrão e pelos granitos paleoproterozóicos Musa e Bannach da Suíte Jamon. As rochas do Granodiorito Rio Maria do domínio a leste de Bannach exibem aspecto bastante homogêneo, textura equigranular média a grossa e, de uma forma geral, foliação de direção WNW-ESE, além de marcante presença de enclaves máficos (feição comum a todas as ocorrências do GDrm). O GDrm é formado essencialmente por epidoto-biotita-hornblenda granodiorito com variações bastante localizadas para monzogranitos. Associa-se com rochas máficas acamadadas e intermediárias, as quais não serão discutidas no presente trabalho. As amostras do GDrm estudadas apresentam caráter metaluminoso e características afins com as das séries cálcico-alcalinas em certos diagramas, porém mostram conteúdos mais baixos de $\mathrm{Al}_{2} \mathrm{O}_{3}$ e $\mathrm{CaO}$ e mais altos de $\mathrm{MgO}, \mathrm{Cr}$ e Ni do que estas séries, assemelhando-se geoquimicamente às suítes sanukitóides da Província Superior do Canadá. Os conteúdos e padrões de elementos terras raras das rochas do GDrm são caracterizados pelo enriquecimento acentuado em elementos terras raras leves (ETRL) em relação aos elementos terras raras pesados (ETRP), com forte a moderado fracionamento de ETRP $\left(\mathrm{La}^{\mathrm{Y}} \mathrm{Yb}=15,52\right.$ a 44,38). O GDrm da região estudada é bastante similar em termos petrográficos, geoquímicos e de aspectos de campo às demais ocorrências dessa unidade no TGGRM. Entre as diferenças sutis observadas, destacam-se a ocorrência mais restrita de termos monzograníticos e a presença de granodioritos mais ricos em quartzo na área-tipo. As principais carcterísticas geoquímicas das rochas do Granodiorito Rio Maria das demais ocorrências são muito semelhantes às daquelas estudadas porém as primeiras mostram-se comparativamente mais evoluídas, com valores mais elevados de $\mathrm{SiO}_{2}, \mathrm{Al}_{2} \mathrm{O}_{3}, \mathrm{~K}_{2} \mathrm{O}$ e $\mathrm{Rb}$ e mais baixos de $\mathrm{Na}_{2} \mathrm{O}, \mathrm{CaO}$ e \#Mg.
\end{abstract}

Palavras-Chaves: Cráton Amazônico, Séries Sanukitoides, Granodiorito, Arqueano.

\begin{abstract}
PETROGRAPHY AND GEOCHEMISTRY OF THE RIO MARIA GRANODIORITE IN THE BANNACH REGION AND COMPARISONS WITH THE OTHER OCCURRENCES IN THE RIO MARIA GRANITE-GREENSTONE TERRANE - PARÁ. The Archean Rio Maria Granodiorite (RMGD) is exposed in large domains of the Rio Maria Granite-Greenstone Terrane (RMGGT), southeastern Amazonian craton. New occurrences of the Archean Rio Maria Granodiorite situated to the east of Bannach town, immediately to the west of the type-area, have been studied. In the Bannach area, the RMGD is intrusive in the greenstone belts of the Andorinhas Supergroup. The field relationships between the RMGD and Archean tonalites and trondhjemites (TTGs) are not conclusive and it is admitted that both have similar ages. Leucogranites correlated with the Archean Xinguara and Mata Surrão granites and the Paleoproterozoic Musa and Bannach granites of the Jamon Suite are intrusive in the RMGD.

The rocks of the RMGD exposed in the studied area are quite uniform, displaying medium- coarse-evengrained texture, a generally weak or WNW-ESE striking foliation, and including systematically mafic enclaves, a feature observed in all occurrences of the Rio Maria Granodiorite. The Rio Maria Granodiorite in the Bannach area is formed dominantly of epidote-biotite-hornblende granodiorite with subordinate monzogranite. Intermediate and layered mafic rocks are associated with the granodiorite assemblage, but they will not be discussed in the present paper. The RMGD display metaluminous character and some geochemical characteristics in common with calc-alkaline series, however it has lower $\mathrm{Al}_{2} \mathrm{O}_{3}$ and $\mathrm{CaO}$ and higher $\mathrm{MgO}, \mathrm{Cr}$ and $\mathrm{Ni}$ contents compared to calc-alkaline series, approaching geochemically the sanukitoid series. Rare earth element patterns are characterized by a pronounced enrichment in light rare earth elements (LREE) and strong to moderate fractionation of heavy rare earth elements (HREE) $\left(\mathrm{La} / \mathrm{Yb}_{\mathrm{n}}=15,52\right.$ a 44,38). Field aspects and petrographic and geochemical characteristics of the RMGD of the studied area are very similar to those of other RMGD occurrences elsewhere. Some subtle differences are the more restricted distribution of monzogranitic rocks in the Bannach domain and the higher quartz content in the granodiorite of the type-area. The major geochemical characteristics of the rocks of different occurrences of the RMGD are very similar, but compared to the studied area, in the type-area and other domains, the dominant granodiorites are more evolved, showing higher $\mathrm{SiO}_{2}, \mathrm{Al}_{2} \mathrm{O}_{3}, \mathrm{~K}_{2} \mathrm{O}$ and $\mathrm{Rb}$ and lower $\mathrm{Na}_{2} \mathrm{O}, \mathrm{CaO}$, and $\# \mathrm{Mg}$.
\end{abstract}

Keywords: Amazonian Craton, Sanukitoid Series, Granodiorite, Archean.

INTRODUÇÃO Os terrenos granito-greenstone arqueanos de vários locais do mundo são constituídos fundamentalmente por associações granitóides dominadas por rochas que formam as clássicas associações TTG e por greenstone belts (Condie
\& Hunter 1976, Dall'Agnol et al. 1997a, Althoff et al. 2000, Souza et al. 2001). O Terreno Granito-Greenstone de Rio Maria (TGGRM) apresenta um magmatismo granitóide bastante expressivo com idades variando de $2,97 \mathrm{Ga}$ a $1,88 \mathrm{Ga}$. Uma das

1 - Grupo de Pesquisa Petrologia de Granitóides (GPPG) - Centro de Geociências (CG) - Universidade Federal do Pará (UFPA). Caixa Postal 8608, Cep-66075-900, Belém, Pará.mao@ufpa.br

2 - Departamento de Geoquímica e Petrologia - CG - UFPA. robdal@ufpa.br

3 - Programa de Pós-Graduação em Geologia e Geoquímica - PPGG - CG - UFPA

4 - Centro de Ciências Exatas e Tecnológicas - CENTRO 6, Programa de Pós-Graduação em Geologia - Universidade do Vale do Rio dos Sinos (UNISINOS). Caixa

Postal 275, Cep 93022-000, São Leopoldo, Rio Grande do Sul. althoff@euler.unisinos.br 
unidades relacionadas a este magmatismo é o Granodiorito Rio Maria (GDrm), que foi estudado e caracterizado petrológica e estruturalmente a sul de Rio Maria (Medeiros 1987, Medeiros \& Dall'Agnol 1988), na região de Xinguara (Leite 2001) e na região de Marajoara (Althoff et al. 2000). Porém, até o presente estudo a porção do Granodiorito Rio Maria que aflora na área imediatamente a oeste da sua área-tipo, localizada a leste da sede do município de Bannach (Figura 1) não dispunha de detalhe nem tampouco de informações sobre suas características petrográficas e geoquímicas. Pouco se conhecia igualmente sobre as rochas máficas e intermediárias que ocorrem associadas ao GDrm naquela área. Entretanto, tais rochas não serão abordadas neste trabalho, por não serem seu objetivo. O presente trabalho visa a caracterização geológica, petrográfica e geoquímica das rochas do GDrm que ocorrem a leste de Bannach, buscando-se melhor caracterização desta porção do GDrm, bem como sua comparação com as rochas estudadas nos demais domínios do Terreno Granito-Greenstone de Rio Maria (TGGRM). Pretende-se com isso contribuir para a carcterização dos granodioritos com afinidades sanukitóides presentes no TGGRM.

CONTEXTO GEOLÓGICO REGIONAL A região de Bannach situa-se na porção centro-oeste do Terreno GranitoGreenstone de Rio Maria. Este apresenta como unidade supracrustal os greenstone belts do Supergrupo Andorinhas, constituídos dominantemente por komatítos e basaltos toleíticos, com idades que variam de 2,97 a 2,9 Ga, correspondendo, assim como a geração do Tonalito Arco Verde e Complexo Tonalítico Caracol, ao evento geológico mais antigo deste terreno (Pimentel \& Machado 1994, Macambira \& Lafon 1995). O evento que produziu os greenstone belts do TGGRM foi dominantemente vulcânico e de caráter máfico-ultramáfico, com contribuições ácidas e sedimentares subordinadas.

No intervalo entre 2,98 e 2,92 Ga foram originados, também, corpos plutônicos da série TTG, agrupados no Tonalito Arco Verde que apresenta idade U-Pb em zircão de $2957+25 /$ $21 \mathrm{Ga}$ (Macambira 1992) e $\mathrm{Pb} / \mathrm{Pb}$ em zircão de $2948 \pm 7 \mathrm{Ma}$, $2965 \pm 1 \mathrm{Ma}, 2981 \pm 1 \mathrm{Ma}$ e $2988 \pm 5 \mathrm{Ma}$ (Rolando \& Macambira 2003) e corresponde, juntamente com o Complexo Tonalítico Caracol, de idades de $2948 \pm 5$ a $2924 \pm 2$ Ma (Leite 2001), aos granitóides mais antigos do TGGRM. Posteriormente, entre 2,87-2,86 Ga, a região foi afetada por novo evento magmático que gerou os granitóides TTG mais jovens, representados pelo Trondhjemito Mogno, Trondhjemito Água Fria e Tonalito Parazônia (Huhn et al. 1988, Souza 1994, Leite 2001), granitóides sanukitóides com alto $\mathrm{Mg}$ tipo Granodiorito Rio Maria (Medeiros \& Dall'Agnol 1988, Souza 1994, Althoff 1996, Leite 2001), além dos leucogranitos potássicos, de afinidade cálcico-alcalina, Mata Surrão (Duarte 1992), Xinguara (Leite et al. 2004) e Guarantã (Althoff 1996, Althoff et al. 2000). Após a geração destes granitóides, formaram-se as rochas sedimentares do Grupo Rio Fresco.

Durante o Paleoproterozóico, em torno de 1,88 Ga, a região de Rio Maria foi palco de magmatismo granítico anorogênico (Dall'Agnol et al. 1997a, 2005), representado pela Suíte Jamon (granitos Jamon, Musa, Redenção, Marajoara e Bannach) e por diques félsicos a máficos localmente compostos, que são contemporâneos dos granitos proterozóicos, e que seccionam tanto as unidades arqueanas quanto os granitos paleoproterozóicos .

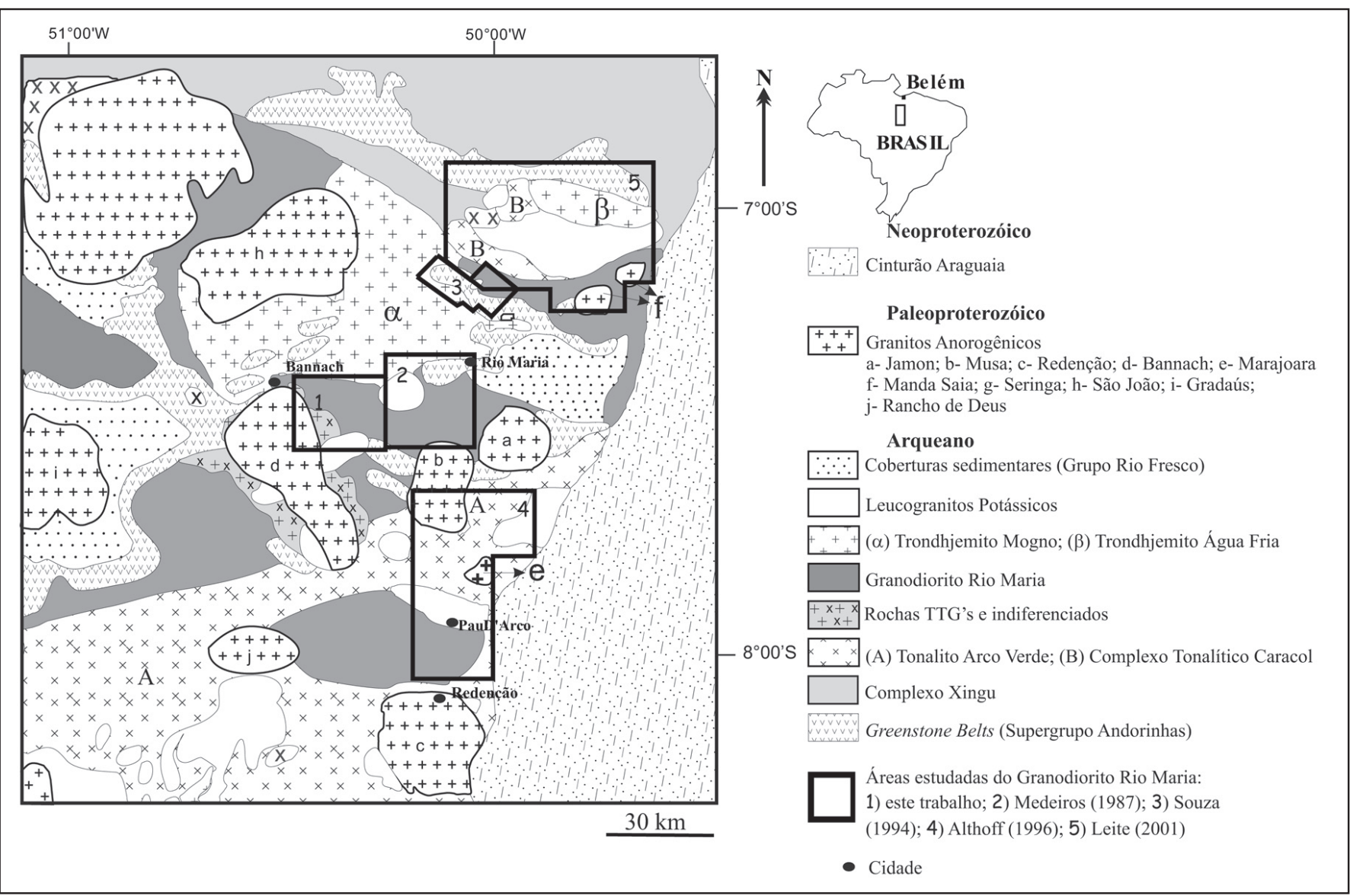

Figura 1 - Mapa geológico do Terreno Granito-Greenstone de Rio Maria reproduzido a partir de Oliveira (2005, modificado); Fontes: Huhn et al. 1988, Souza 1994, CPRM 2000, Althoff et al. 2000, Leite 2001. 
CARACTERÍSTICAS DO GRANODIORITO RIO MARIA

Feições estruturais e de campo A estrutura principal observada no Granodiorito Rio Maria é uma foliação subvertical com orientação geral NW-SE a WNW-ESE concordante com a foliação regional, indicada pela orientação dos minerais e salientada muitas vezes pela presença de enclaves máficos deformados (Souza 1994). A foliação pode ser magmática ou formada em condições subsolidus. O granodiorito apresenta desde rochas fortemente orientadas, até outras praticamente isotrópicas (Medeiros 1987, Althoff 1996). Em escala mesoscópica os melhores marcadores da foliação do GDrm são enclaves máficos centimétricos a métricos que permitem melhor definição do estilo de deformação sofrido pelo GDrm. Segundo Leite (2001), os enclaves podem ter forma achatada ou estirada. A foliação magmática é rara, sendo definida pela orientação preferencial de cristais primários de feldspatos orientados, mas não recristalizados, em rocha em que quartzo ainda guarda sua disposição intersticial, indicando a origem submagmática da foliação. Rochas de aspecto isotrópico podem apresentar em lêmina delgada foliação definida pela orientação de cristais de quartzo, feldspatos e minerais máficos. Outras estruturas identificadas no GDrm são dobras em veios, bandas de cisalhamento e fendas de tensão. Leite (2001) descreve, ainda, zonas de cisalhamento de baixo ângulo no GDrm na região de Xinguara.

Petrografia O Granodiorito Rio Maria apresenta homogeneidade textural e, em geral, cor cinza clara com tons esverdeados.
Sua textura é granular hipidiomórfica média a grossa, estando localmente obliterada pela deformação, com feldspatos passando a apresentar formas amendoadas e sendo envolvidos por faixas de minerais máficos e quartzo.

As fácies identificadas no GDrm mostram-se dominantemente granodioríticas, e subordinadamente, monzograníticas, quartzo-dioríticas e dioríticas (Medeiros 1987, Althoff 1996, Leite 2001). As principais fácies identificadas são: biotita-hornblenda diorito (BHDr), hornblenda-biotita-quartzo diorito (HBQzDr), hornblenda-biotita granodiorito (HBGd), biotitahornblenda granodiorito (BHGd), biotita granodiorito (BGd) e hornblenda-biotita monzogranito (HBMzG). Os dioritos e quartzo dioritos são pouco abundantes. De acordo com os dados modais, as rochas do Granodiorito Rio Maria seguem o trend da série cálcico-alcalina granodiorítica de Lameyre \& Bowden (1982).

Em termos microscópicos, o Granodiorito Rio Maria é caracterizado por mostrar textura granular hipidiomórfica que varia de média a grossa, geralmente com boa preservação, evidenciando sua fraca deformação. Seus constituintes essenciais são plagioclásio, álcali-feldspato e quartzo; anfibólio e biotita são varietais; como acessórios principais têm-se opacos, epidoto, alanita, titanita, zircão e apatita. Dados de geobarometria em anfibólio (Leite 2001) indicam pressão de cerca de $3 \mathrm{kbar}$, para o GDrm, correspondente a cristalização em profundidade de $10 \mathrm{~km}$. Com base nisso, Leite (2001) admite colocação na transição entre os ambientes epizonal e mesozonal. Além disso, estima que o processo de colocação não foi diapírico.

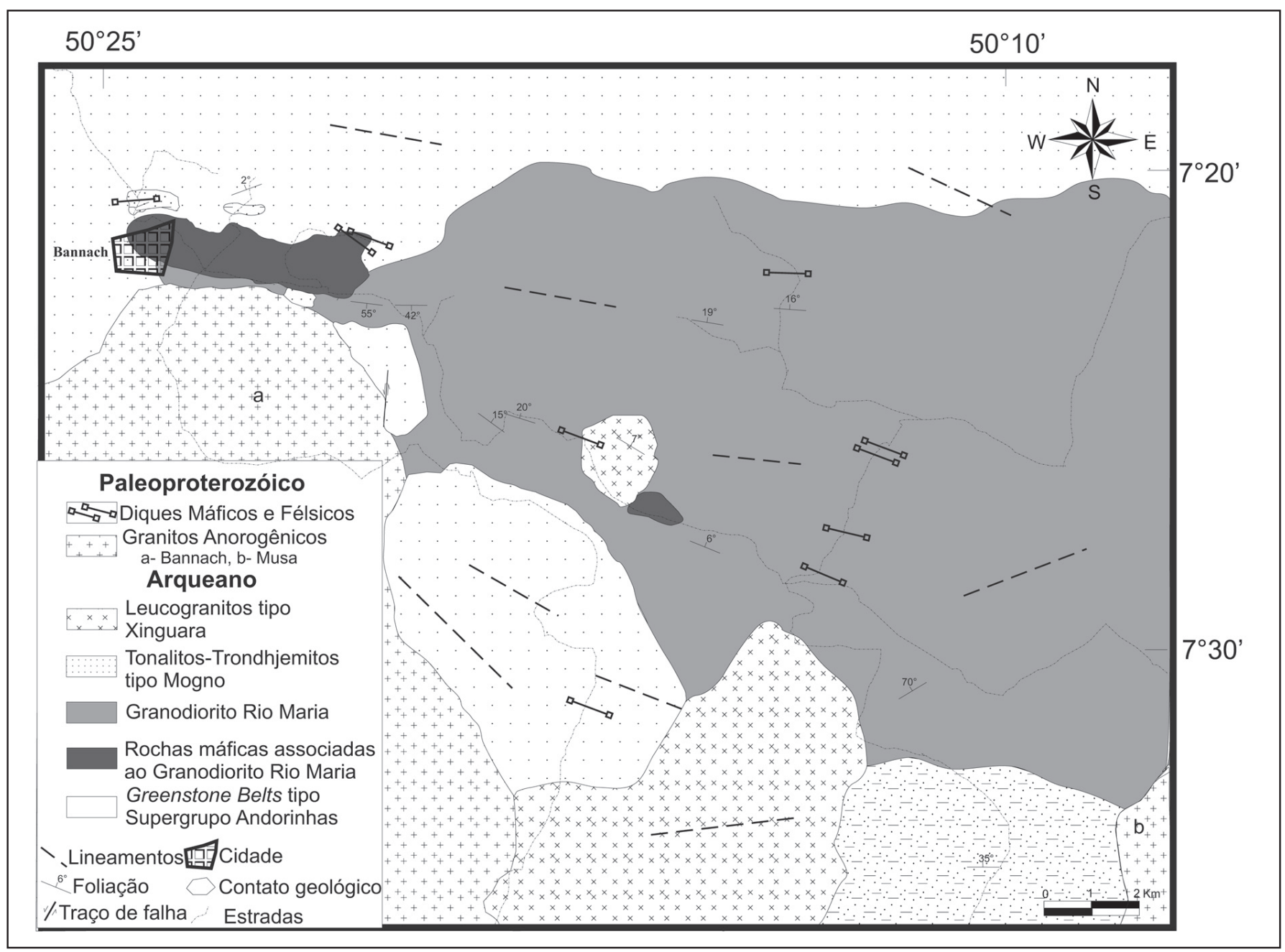

Figura 2-Mapa geológico da região de Bannach. 
Geoquímica $\mathrm{O}$ Granodiorito Rio Maria tem caráter metaluminoso e diagramas AFM e K-Na-Ca sugerem que possui afinidade geoquímica com a série cálcico-alcalina. Suas variedades revelam enriquecimento relativo em $\mathrm{Ba}, \mathrm{Rb}$ e alta razão $\mathrm{Rb} / \mathrm{Sr}$, quando comparadas às suítes tonalítica-trondhjemíticagranodioríticas (TTG). Tal aspecto foi destacado primeiramente por Althoff et al. (1991, 1995), quando compararam o GDrm da área tipo e aquele de Marajoara com o Tonalito Arco Verde, e por Leite (2001) quando do estudo dos granitóides arqueanos da região de Xinguara. Estes autores descartaram a possibilidade do GDrm ser a fração granodiorítica mais evoluída da suíte TTG, sendo que Medeiros (1987) e Medeiros \& Dall'Agnol (1988) já haviam interpretado o GDrm como uma associação cálcico-alcalina, diferindo neste aspecto das associações TTG.

Com base em aspectos petrográficos e geoquímicos, Medeiros (1987) e Medeiros \& Dall'Agnol (1988) propuseram dois "trends" de diferenciação: 1) geração de BGd a partir de BHGd com fracionamento de hornblenda, plagioclásio cálcico e biotita; 2) geração de HBMzG também a partir de BHGd, porém com enriquecimento em potássio. $\mathrm{O}$ primeiro "trend" não foi observado nas demais áreas de ocorrência do GDrm, sendo muito provável que a origem do BGd seja distinta daquela do GDrm. Por essa razão tais rochas não serão consideradas nas comparações apresentadas a seguir.

Segundo Leite (2001), a afinidade geoquímica do Granodiorito Rio Maria com as séries cálcico-alcalinas típicas é enganosa, pois as associações cálcico-alcalinas típicas de margens continentais são bem mais ricas em $\mathrm{Al}_{2} \mathrm{O}_{3}$ e $\mathrm{CaO}$ e mais pobres em $\mathrm{MgO}, \mathrm{Cr}$ e Ni. Antes disso, Althoff et al. (1995) já haviam mostrado que o Granodiorito Rio Maria possui características químicas similares aos granodioritos arqueanos ricos em $\mathrm{Mg}$ (suítes sanukitóides), definidos por Stern et al. (1989) e Stern \& Hanson (1991), distinguindo-se claramente dos granitóides TTG. A comparação geoquímica entre o GDrm e os granodioritos arqueanos ricos em $\mathrm{Mg}$ da suíte sanukitóide revela nítidas semelhanças.

GEOLOGIA DA REGIÃO DE BANNACH A geologia da região de Bannach foi discutida inicialmente no relatório de pesquisa mineral tratando da área de Pedra Preta (Docegeo 1982), e posteriormente, integrada em síntese regional (Docegeo 1988). Além destes estudos, o mapeamento regional da Folha Xinguara (SB-22-Z-C), executado pela Companhia de Pesquisa e Recursos Minerais (CPRM 2000), dentro do Programa Levantamentos Geológicos do Brasil, contribuiu para caracterizar e individualizar as principais unidades ocorrentes na região. Pesquisas um pouco mais detalhadas, a sul da região estudada, foram realizadas por Duarte (1992), na área tipo do Granito Mata Surrão.

No mapeamento da região a leste da cidade de Bannach, efetuado durante a dissertação de mestrado do primeiro autor deste trabalho (Figura 2, Oliveira 2005), foram identificadas rochas supracrustais (seqüências metavulcano-sedimentares) e granitóides variados, dentre os quais, o Granodiorito Rio Maria e rochas máficas e intermediárias associadas. As rochas supracrustais identificadas pertencem à sequência Pedra Preta do Supergrupo Andorinhas, aflorantes no sudeste da área ou em ocorrências menores a norte e nordeste de Bannach. Dentre os granitóides, além do GDrm, foram identificados tonalitos-trondhjemitos tipo TTG, leucogranitos potássicos, diques que cortam as unidades arqueanas e os corpos graníticos paleoproterozóicos Bannach (Almeida 2005) e Musa (Dall'Agnol et al. 2005).

Uma parte expressiva da área, correspondente às porções central e leste é ocupada pelo GDrm e rochas máficas a intermediárias associadas, ocorrendo subordinadamente as demais unidades (Figura 2). Os granitóides reconhecidos foram correla- cionados a unidades já mapeadas. Em mapeamentos realizados anteriormente, mesmo em escalas menores, algumas das unidades identificadas já haviam sido reconhecidas (Docegeo 1982, 1988, CPRM 2000). Os granitóides tonalíticos-trondhjemíticos mapeados por Oliveira (2005), embora sem relações estratigráficas de campo conclusivas e sem idade definida por datações geocronológicas, foram tentativamente correlacionados ao Trondhjemito Mogno (Huhn et al. 1988), descrito em trabalhos anteriores na porção norte da área (CPRM 2000). Rochas TTG similares foram identificadas durante o mapeamento também nas porções noroeste e centro-sul da área (Figura 2). Leucogranitos potássicos similares aos granitos arqueanos Xinguara (Leite 2001) e Mata Surrão (Duarte 1992) ocorrem na porção sul da área e formam um corpo menor na sua porção central.

\section{GRANODIORITO RIO MARIA DA REGIÃO DE BAN-}

NACH O Granodiorito Rio Maria ocupa uma extensa faixa central que se alarga de oeste para leste da área (Figura 2). Apresenta caráter intrusivo na seqüência Pedra Preta, relações de campo não conclusivas com os tonalitos-trondhjemitos tipo Mogno, e é intrudido pelo leucogranito tipo Xinguara e granitos paleoproterozóicos.

As relações de campo do Granodiorito Rio Maria típico com o leucogranito tipo Xinguara levam a crer que o primeiro foi cortado por veios leucograníticos ligados aos granitos. Relações de campo, observadas neste trabalho, mostram localmente enclaves de tonalitos-trondhjemitos no GDrm. Admitindo-se que se trata de rochas do Trondhjemito Mogno, isso seria contraditório com as relações entre o Trondhjemito Mogno e o GDrm descritas na área-tipo do primeiro, bem como com dados geocronológicos (Pimentel \& Machado 1994, Medeiros et al. 1987, Docegeo 1988, Huhn et al 1988, Souza et al. 1988, 1990) que indicam caráter intrusivo do trondhjemito no GDrm. Há porém a possibilidade de que parte das associações TTG identificadas na área seja mais antiga e correlacionável ao Tonalito Arco Verde e não ao Tronchjemito Mogno. Portanto, sem trabalhos mais detalhados de campo e datações geocronológicas as relações entre estas unidades, não poderão ser esclarecidas na área mapeada.

As rochas do GDrm apresentam textura fanerítica, equigranular média a grossa e são essencialmente granodioríticas com variações monzograníticas muito subordinadas. Os termos granodioríticos apresentam coloração cinza clara com tons esverdeados, e os monzogranitos exibem ora coloração similar, ora coloração rosada, em resposta ao maior conteúdo modal de feldspato alcalino. A presença de enclaves máficos, orientados ou não, é uma feição constante no granodiorito.

O Granodiorito Rio Maria, de uma forma geral, apresenta uma foliação de baixo ângulo $\left(6^{\circ}\right.$ a $\left.19^{\circ}\right)$ de direção WNW-ESE (Figura 2), fraca a marcante, devido à orientação dos minerais ferro-magnesianos e, por vezes, enclaves máficos. Tal foliação de baixo ângulo não é comum nas demais ocorrências do GDrm.

A disposição concordante entre as foliações das demais unidades arqueanas que ocorrem na área de trabalho e as do GDrm, somadas a observações de estudos anteriores (Souza 1994, Althoff 1996, Leite 2001), indicam que a foliação do GDrm seja produto de processo deformacional regional, o qual teria afetado igualmente as demais unidades arqueanas. De acordo com Leite (2001), a foliação presente nas rochas do GDrm, na região de Xinguara, formou-se a partir do estágio submagmático até o estágio subsolidus.

PETROGRAFIA Composições modais e classificação Foram realizadas análises modais de onze amostras, sendo que os cristais de epidoto tidos como primários foram contados separadamente dos secundários (alteração de plagioclásio). A principal fácies identificada é epidoto-biotita-hornblenda gra- 
Tabela 1 - Composições modais das diversas fácies do Granodiorito Rio Maria da região de Bannach. Abreviações: : A - Álcalifeldspato; P - Plagioclásio; MzG-Monzogranito; Gd - Granodiorito; Ep - epidoto; Hb-hornblenda; Bt-biotita; $p$ - primário; s - secundário; * recalculado a 100\%; 1-Com base, em média de 1800 pontos por amostra; X = mineral presente na rocha, mas não registrado na contagem modal; - = mineral não observado.

\begin{tabular}{|c|c|c|c|c|c|c|c|c|c|c|c|c|c|c|}
\hline Fácies & \multicolumn{8}{|c|}{ EpBtHbGd } & \multicolumn{3}{|c|}{ EpHbBtGd } & \multicolumn{3}{|c|}{ EpBtHbMzG } \\
\hline Amostra & MFR & MFR & MFR & ADR & MFR & MFR & MFR & & MFR & MFR & & MFR & MFR & \\
\hline Mineral & 32 & $26 \mathrm{~A}$ & $27 \mathrm{~A}$ & $3 \mathrm{~A}$ & 114 & $80 \mathrm{~A}$ & 112 & Média & $91 \mathrm{~A}$ & $62 \mathrm{~A}$ & Média & 29 & 111 & Média \\
\hline Microclínio & 15,9 & 18 & 8,3 & 15,2 & 9,3 & 9,1 & 20,3 & 13,7 & 16,1 & 11,7 & 13,9 & 23,1 & 24,2 & 23,6 \\
\hline Quartzo & 16,1 & 25,6 & 24 & 23,2 & 19,2 & 20,5 & 17,6 & 20,9 & 18,9 & 17,5 & 18,2 & 22,2 & 19,6 & 20,9 \\
\hline Plagioclásio & 49,7 & 37,2 & 44,6 & 36,8 & 46,6 & 48,2 & 45,3 & 44,1 & 40,3 & 47,9 & 44,1 & 37,5 & 36,2 & 36,8 \\
\hline Hornblenda & 9,8 & 8,2 & 11,8 & 11,1 & 12,7 & 8,2 & 8,8 & 10,1 & 10,2 & 7,6 & 8,9 & 8,1 & 8,7 & 8,4 \\
\hline Biotita & 4,4 & 7,7 & 7,8 & 7,5 & 8,2 & 7,2 & 4,2 & 6,7 & 11,3 & 10,7 & 11 & 4,8 & 7,6 & 6,2 \\
\hline Epidoto $^{(\mathrm{p})}$ & 1,2 & 0,6 & 0,7 & 1,8 & 1,1 & 1,9 & 1,1 & 1,2 & 0,3 & 1,3 & 0,8 & 0,7 & 0,8 & 0,7 \\
\hline Epidoto $^{(\mathrm{s})}$ & 1,1 & 1,3 & 1 & 2 & 0,8 & 2,6 & 1,4 & 1,5 & 0,8 & 1,5 & 1,1 & 1,1 & 1,1 & 1,1 \\
\hline Opacos & - & - & 0,2 & $\mathrm{x}$ & 0,1 & $\mathrm{x}$ & $\mathrm{x}$ & $\mathrm{x}$ & - & - & - & 0,2 & $\mathrm{x}$ & 0,1 \\
\hline Titanita & 0,6 & 0,3 & 0,4 & 0,9 & 0,7 & 0,7 & 0,2 & 0,5 & 1,1 & 0,8 & 0,9 & 1,1 & 0,6 & 0,8 \\
\hline Apatita & 0,2 & 0,4 & 0,7 & 0,2 & 0,2 & 0,8 & 0,2 & 0,4 & 0,1 & 0,3 & 0,2 & 0,3 & 0,1 & 0,2 \\
\hline Allanita & 0,3 & 0,5 & 0,1 & 0,1 & $\mathrm{x}$ & $\mathrm{x}$ & 0,1 & 0,1 & $\mathrm{x}$ & 0,2 & 0,1 & 0,5 & 0,6 & 0,5 \\
\hline Carbonato & - & - & 0,1 & - & - & - & $\mathrm{x}$ & $\mathrm{x}$ & $\mathrm{x}$ & $\mathrm{x}$ & $\mathrm{x}$ & - & 0,1 & $\mathrm{x}$ \\
\hline Acessórios & $\mathrm{x}$ & $\mathrm{x}$ & $\mathrm{x}$ & - & $\mathrm{x}$ & $\mathrm{x}$ & $\mathrm{x}$ & $\mathrm{x}$ & $\mathrm{x}$ & $\mathrm{x}$ & $\mathrm{x}$ & 0,1 & $\mathrm{x}$ & $\mathrm{x}$ \\
\hline Máficos & 16,5 & 17,7 & 21,8 & 21,6 & 23 & 18,8 & 14,6 & 19,1 & 23 & 20,9 & 22 & 15,7 & 18,4 & 17,1 \\
\hline $\mathrm{A}+\mathrm{P}$ & 65,6 & 56,5 & 53,9 & 54 & 56,7 & 59,9 & 67 & 59,2 & 57,2 & 61,1 & 59,2 & 61,7 & 61,5 & 61,6 \\
\hline Microclínio* & 19,2 & 21,9 & 10,7 & 19,7 & 12,3 & 11,3 & 24,0 & 17,2 & 21,2 & 14,9 & 18,0 & 27,5 & 29,8 & 28,6 \\
\hline Quartzo* & 19,4 & 31,2 & 30,8 & 30,1 & 25,3 & 25,5 & 20,8 & 26,2 & 24,8 & 22,3 & 23,5 & 26,5 & 24,2 & 25,4 \\
\hline Plagioclásio* & 61,4 & 46,9 & 58,5 & 50,3 & 62,5 & 63,2 & 55,2 & 56,6 & 54,0 & 62,8 & 58,5 & 46,0 & 46,0 & 46,0 \\
\hline
\end{tabular}

Abreviações: A - Álcali-feldspato; P - Plagioclásio; MzG-Monzogranito; Gd - Granodiorito; Ep - epidoto; Hb-hornblenda; Bt-biotita; p - primário; s secundário; * recalculado a 100\%; 1-Com base, em média de 1800 pontos por amostra; X = mineral presente na rocha, mas não registrado na contagem modal; $=$ mineral não observado.

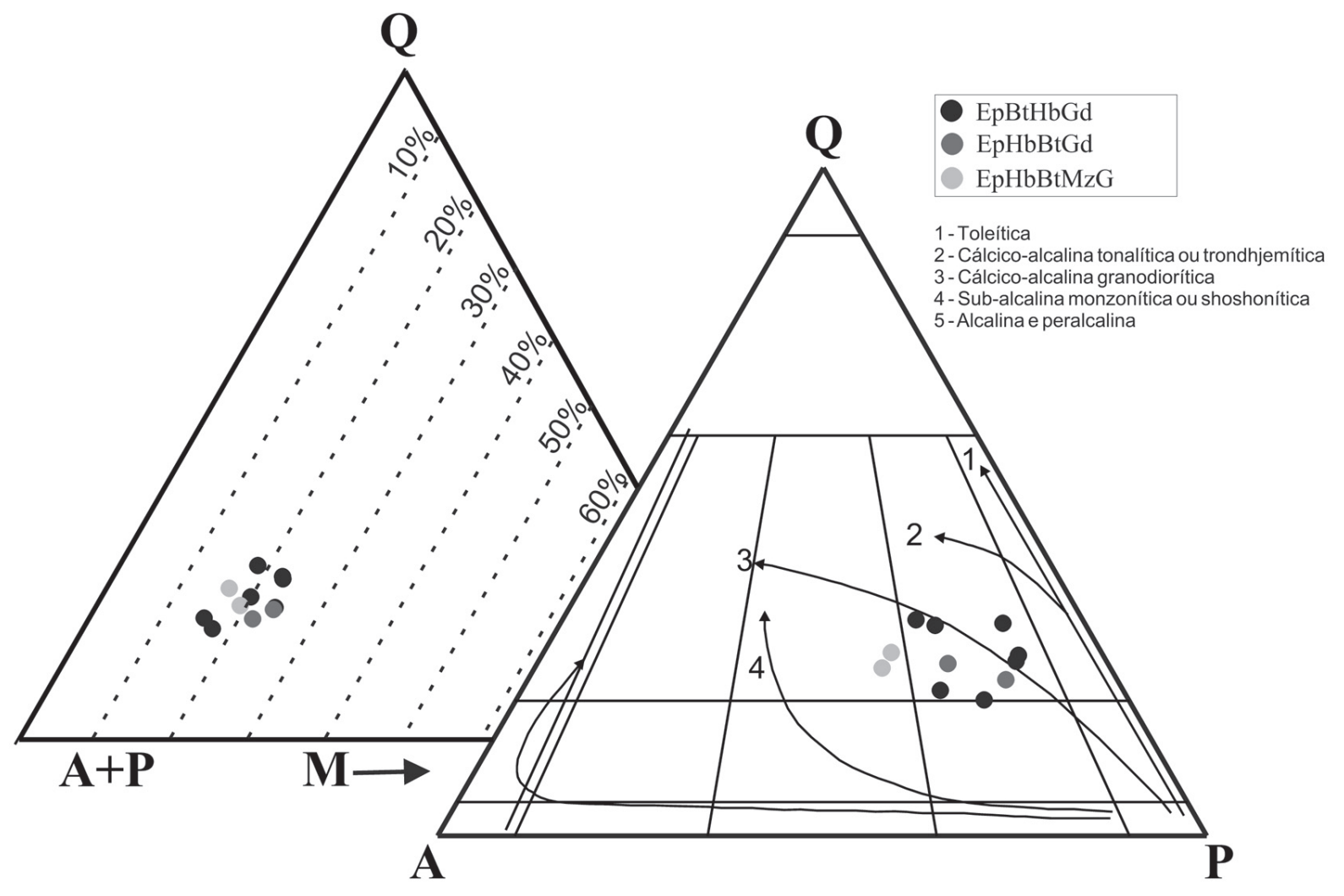

Figura 3 - Diagramas modais Q-A-P e Q-(A+P)-M (Streckeisen 1976) para o Granodiorito Rio Maria da região de Bannach. 1 a 5 - Séries de granitóides e respectivos trends evolutivos (Lameyre \& Bowden 1982, Bowden et al. 1984). 
Tabela 2 - Análises químicas de amostras do Granodiorito Rio Maria da região de Bannach. Abreviações: \#Mg=\%MgOmol/ $(\% \mathrm{MgOmol}+\% \mathrm{FeOtmol}) ; A=$ Epidoto-biotita-hornblenda granodiorito; $B=$ Epidoto-hornblenda-biotita granodiorito; $C=$ Epidoto-biotita-hornblenda monzogranito.

\begin{tabular}{|c|c|c|c|c|c|c|c|c|c|}
\hline \multicolumn{10}{|c|}{ Granodiorito Rio Maria (GDrm) } \\
\hline & MFR-114 (A) & MFR-27 (A) & MFR-111 (C) & MFR-29(C) & $\overline{\mathrm{ADR}-3 \mathrm{~A}(\mathrm{~A})}$ & MFR-112 (A) & MFR-91A (B) & MFR-80A (A) & Média \\
\hline$\overline{\mathrm{SiO}_{2}}$ & $\overline{62,52}$ & 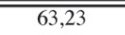 & 63,66 & 63,66 & 63,9 & 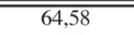 & 64,72 & 66,49 & 64,10 \\
\hline $\mathrm{TiO}_{2}$ & 0,46 & 0,49 & 0,42 & 0,45 & 0,43 & 0,42 & 0,39 & 0,33 & 0,42 \\
\hline $\mathrm{Al}_{2} \mathrm{O}_{3}$ & 15,23 & 14,82 & 14,87 & 14,84 & 14,82 & 14,65 & 14,98 & 14,55 & 14,85 \\
\hline $\mathrm{Fe}_{2} \mathrm{O}_{3}$ & 2,91 & 2,8 & 2,81 & 3 & 2,91 & 2,86 & 2,71 & 2,27 & 2,78 \\
\hline $\mathrm{FeO}$ & 1,97 & 1,89 & 1,64 & 1,48 & 1,65 & 1,47 & 1,49 & 1,32 & 1,61 \\
\hline $\mathrm{MnO}$ & 0,07 & 0,06 & 0,06 & 0,06 & 0,06 & 0,06 & 0,06 & 0,05 & 0,06 \\
\hline $\mathrm{MgO}$ & 2,61 & 2,49 & 2,31 & 2,31 & 2,39 & 2,28 & 2,06 & 1,85 & 2,29 \\
\hline $\mathrm{CaO}$ & 4,4 & 4,36 & 3,99 & 4,17 & 4,02 & 3,77 & 4,08 & 3,02 & 3,98 \\
\hline $\mathrm{Na}_{2} \mathrm{O}$ & 4,3 & 4,21 & 4,19 & 4,09 & 4,05 & 4,04 & 4,29 & 4,13 & 4,16 \\
\hline $\mathrm{K}_{2} \mathrm{O}$ & 2,93 & 3,01 & 3,32 & 3,22 & 3,21 & 3,44 & 2,98 & 3,75 & 3,23 \\
\hline $\mathrm{P}_{2} \mathrm{O}_{5}$ & 0,17 & 0,15 & 0,15 & 0,14 & 0,14 & 0,15 & 0,12 & 0,14 & 0,15 \\
\hline $\mathrm{PF}$ & 1.6 & 1.8 & 1.9 & 1.9 & 1.8 & 1.5 & 1.5 & 1.4 & 1.68 \\
\hline Total & 99.17 & 99.31 & 99.32 & 99.32 & 99.38 & 99.22 & 99.38 & 99.3 & 99.30 \\
\hline$\overline{\mathrm{Ba}}$ & 1139 & 1175 & 1052 & 1022 & 1098 & 1064 & 1044 & 1089 & 1085 \\
\hline $\mathrm{Sr}$ & 692 & 661 & 615 & 611 & 576 & 567 & 632 & 512 & 608 \\
\hline $\mathrm{Rb}$ & 98 & 103 & 113 & 112 & 109 & 122 & 101 & 116 & 109 \\
\hline $\mathrm{Zr}$ & 113 & 126 & 103 & 131 & 109 & 110 & 113 & 122 & 116 \\
\hline $\mathrm{Y}$ & 16 & 13 & 11 & 15 & 11 & 12 & 17 & 12 & 13 \\
\hline $\mathrm{Nb}$ & 8 & 9 & 8 & 8 & 7 & 11 & 9 & 10 & 9 \\
\hline $\mathrm{Ga}$ & 20 & 20 & 19 & 20 & 20 & 19 & 20 & 19 & 20 \\
\hline Th & 7 & 7 & 7 & 8 & 5 & 11 & 8 & 12 & 8 \\
\hline $\mathrm{Ni}$ & 31 & 29 & 28 & 29 & 31 & 29 & 26 & 25 & 29 \\
\hline $\mathrm{Cr}$ & 48 & 68 & 55 & 96 & 68 & 55 & 41 & 55 & 61 \\
\hline$\overline{\mathrm{La}}$ & 37,3 & 36,9 & 33,7 & 34,3 & 20 & 40,7 & $\overline{53,5}$ & 48 & 38,05 \\
\hline $\mathrm{Ce}$ & 72,8 & 71,9 & 64,1 & 64,1 & 45,7 & 70,8 & 72,2 & 64,2 & 65,73 \\
\hline $\operatorname{Pr}$ & 7,19 & 7,57 & 6,32 & 6,53 & 4,94 & 7,04 & 8,51 & 6,81 & 6,86 \\
\hline $\mathrm{Nd}$ & 27,2 & 27,8 & 22,9 & 24,7 & 21,7 & 25,6 & 31,6 & 23,9 & 25,68 \\
\hline Sm & 4,4 & 4,9 & 3,7 & 4,3 & 3,7 & 3,9 & 4,5 & 3,4 & 4,10 \\
\hline $\mathrm{Eu}$ & 1,25 & 1,35 & 1,06 & 1,14 & 1,05 & 1,07 & 1,3 & 0,95 & 1,15 \\
\hline Gd & 3,47 & 3,56 & 2,9 & 3,2 & 2,63 & 2,71 & 3,37 & 2,43 & 3,03 \\
\hline $\mathrm{Tb}$ & 0,56 & 0,53 & 0,42 & 0,47 & 0,41 & 0,4 & 0,52 & 0,36 & 0,46 \\
\hline Dy & 2,41 & 2,19 & 1,92 & 2,19 & 1,86 & 1,9 & 2,31 & 1,56 & 2,04 \\
\hline Ho & 0,48 & 0,42 & 0,34 & 0,42 & 0,41 & 0,4 & 0,49 & 0,32 & 0,41 \\
\hline $\mathrm{Er}$ & 1,3 & 1,15 & 0,92 & 1,19 & 1,02 & 0,92 & 1,25 & 0,81 & 1,07 \\
\hline $\mathrm{Tm}$ & 0,14 & 0,17 & 0,11 & 0,17 & 0,1 & 0,23 & 0,17 & 0,12 & 0,15 \\
\hline $\mathrm{Yb}$ & 1 & 1,06 & 0,92 & 1,09 & 0,87 & 0,83 & 0,99 & 0,73 & 0,94 \\
\hline $\mathrm{Lu}$ & 0,16 & 0,16 & 0,11 & 0,15 & 0,14 & 0,15 & 0,15 & 0,13 & 0,14 \\
\hline$(\mathrm{La} / \mathrm{Yb})_{\mathrm{n}}$ & 25,18 & 23,5 & 24,72 & 21,24 & 15,52 & 33,1 & 36,48 & 44,38 & 28,02 \\
\hline$(\mathrm{La} / \mathrm{Sm})_{\mathrm{n}}$ & 5,34 & 4,74 & 5,73 & 5,02 & 3,4 & 6,57 & 7,49 & 8,89 & 5,90 \\
\hline$(\mathrm{Dy} / \mathrm{Yb})_{\mathrm{n}}$ & 1,57 & 1,34 & 1,36 & 1,31 & 1,39 & 1,49 & 1,52 & 1,39 & 1,42 \\
\hline $\mathrm{Eu} / \mathrm{Eu}^{*}$ & 0,98 & 0,99 & 0,99 & 0,94 & 1,03 & 1,01 & 1,02 & 1,01 & 1,00 \\
\hline $\mathrm{Rb} / \mathrm{Sr}$ & 0,14 & 0,16 & 0,18 & 0,18 & 0,19 & 0,22 & 0,16 & 0,23 & 0,18 \\
\hline $\mathrm{Sr} / \mathrm{Ba}$ & 0,61 & 0,56 & 0,58 & 0,6 & 0,53 & 0,53 & 0,61 & 0,47 & 0,56 \\
\hline $\mathrm{Fe}_{2} \mathrm{O}_{3} / \mathrm{FeO}$ & 1,48 & 1,48 & 1,71 & 2,02 & 1,76 & 1,94 & 1,82 & 1,72 & 1,74 \\
\hline $\mathrm{K}_{2} \mathrm{O} / \mathrm{Na}_{2} \mathrm{O}$ & 0,68 & 0,71 & 0,79 & 0,79 & 0,79 & 0,85 & 0,69 & 0,91 & 0,78 \\
\hline$\# \mathrm{Mg}$ & 0.5 & 0.5 & 0.5 & 0.49 & 0.49 & 0.5 & 0.48 & 0.49 & 0.49 \\
\hline
\end{tabular}

nodiorito (EpBtHbGd), localmente com dominância de biotita sobre anfibólio (EpHbBtGd), ou variações para monzogranito (EpBtHbMzG). Essas variedades não apresentam diferença texturais e mineralógicas marcantes entre si, e nas duas variedades granodioríticas as proporções de máficos se superpõem (Tabela 1), distinguindo-as apenas a proporção relativa de hornblenda e biotita. As amostras granodioríticas possuem teor médio de máficos um pouco superior às monzograníticas (Tabela 1).

O diagrama Q-A-P (Figura 3, campos de Streckeisen 1976) mostram, além da ampla dominância dos granodioritos, que os monzogranitos plotam próximo ao campo granodiorítico. Os conteúdos modais de minerais máficos variam de 14,6\% a 23,0\% (granodioritos). No diagrama Q-A+P-M (Figura 3) nota-se que os conteúdos de máficos das diferentes variedades se superpõem, situando-se em um mesmo intervalo. Destacase, ainda, a ocorrência expressiva de epidoto interpretado como magmático nestas rochas.

Aspectos texturais das principais variedades petrográficas As variedades petrográficas do GDrm apresentam grande similaridade mineralógica e textural e por isso serão descritas conjuntamente.
Plagioclásio e feldspato alcalino formam em geral cristais mais desenvolvidos que os máficos, os quais ora estão levemente orientados, ora formam marcantes aglomerados, por vezes de forma arredondada.

Plagioclásio ocorre como cristais hipidiomórficos a idiomórficos, normalmente milimétricos (até $7 \mathrm{~mm}$ ). Na maioria dos cristais as maclas são apenas parcialmente visíveis devido à forte saussuritização, tendo como principais produtos sericita, epidoto e carbonato. Alguns cristais mostram maior alteração na parte central, sugerindo núcleo mais cálcico e zoneamento normal.

Quartzo ocorre sob duas formas principais: $\mathrm{Qz}_{1}$ apresenta-se como cristais hipidiomórficos médios, com tamanho em torno de 3 a $4 \mathrm{~mm}$; Qz 2 corresponde a cristais produto de recristalização, com dimensões em geral submilimétricas e contatos poligonais. O feldspato alcalino é microclínio, que forma cristais xenomórficos a hipidiomórficos, apresentando contatos irregulares ou raramente retos, variando de submilimétricos (produto de recristalização), até dimensões em torno de $5 \mathrm{~mm}$, com inclusões de quartzo, plagioclásio e, localmente, anfibólio, conferindo-lhe por vezes aspecto poiquilítico.

$\mathrm{O}$ anfibólio, pelo ângulo de extinção em torno de $23^{\circ}, 2 \mathrm{~V}$ 
em torno de $65^{\circ}$ e sinal ótico biaxial negativo, é hornblenda. Althoff (1996) e Leite (2001) obtiveram, por meio de análises de microssonda, composições de magnésio-hornblenda para a maioria dos anfibólios do GDrm nas regiões de Marajoara e Xinguara, respectivamente. Há presença, em graus variáveis, de um processo de transformação do anfibólio gerando biotita e, subordinadamente, epidoto e titanita. Em estágios mais avançados desta transformação não há mais vestígios do cristal original, embora em alguns casos possa ser reconhecida a forma da seção basal da hornblenda.

Biotita ocorre de duas formas principais, uma primária e outra secundária, ligada à trans- formação do anfibólio. A biotita primária é predominante e ocorre como cristais hipidiomórficos a idiomórficos, podendo atingir de 2 a $3 \mathrm{~mm}$ e encontrar-se parcialmente transformada em clorita acompanhada de titanita como produto subordinado.

É comum a associação de epidoto, interpretado como magmático, com cristais primários de biotita, sendo que o primeiro quando em contato com a mica mostra formas euédricas. De acordo com seus aspectos texturais, foram distinguidos os seguintes tipos de epidoto:

Epidoto $1\left(\mathrm{Ep}^{1}\right)$ - cristais essencialmente idiomórficos, prismáticos, por vezes zonados, mostrando afinidade com a biotita, podendo estar associado ou até mesmo incluso nesta. Os cristais de $\mathrm{Ep}^{1}$ possuem contatos retos com a biotita e são idiomórficos quando totalmente inclusos nesta. Quando parcialmente inclusos na biotita, a borda do epidoto em contato com a mica é euédrica, sugerindo equilíbrio entre as duas fases, e torna-se irregular quando em contato com os demais minerais;

Epidoto $2\left(\mathrm{Ep}^{2}\right)$ - pequenos cristais hipidiomórficos a xenomórficos, apresentando zoneamento e envolvendo allanita. Em alguns casos se observam apenas pontos castanhos no centro do agregado de epidoto, interpretados como relíquias de cristais de allanita;

Epidoto $3\left(\mathrm{Ep}^{3}\right)$ - cristais hipidiomórficos a xenomórficos, encontrados isolados ou associados com outros minerais;

Epidoto $4\left(\mathrm{Ep}^{4}\right)$ - cristais muito finos ocorrendo no interior de plagioclásio saussuritizado.

$E^{1}$ e Ep ${ }^{2}$, são similares aos tipos III e II, respectivamente, descritos por Sial (1990) e admitidos por aquele autor como de cristalização magmática.

Os demais minerais acessórios do GDrm são titanita, opacos, allanita, apatita, turmalina e zircão. Ocorrem em geral inclusos nas fases ferromagnesianas mais precoces.

GEOQUÍMICA Elementos maiores e menores As variedades do granodiorito não foram consideradas por não terem sido observados contrastes geoquímicos significativos entre elas. As amostras de granodiorito $(62,52$ a 66,49\%) apresentam variação restrita dos teores de sílica (Tabela 2) e teores relativamente baixos de $\mathrm{Al}_{2} \mathrm{O}_{3}$ (média de 14,86\%), bem inferiores aos das séries cálcico-alcalinas (Irvine \& Baragar 1971, Ringwood 1975). Os conteúdos de $\mathrm{MgO}$ são elevados (2,29\% de média), assim como os teores de $\mathrm{CaO}$ e $\mathrm{Na}_{2} \mathrm{O}\left(>4 \%\right.$ ); os de $\mathrm{K}_{2} \mathrm{O}$ são moderados (média de 3,23\%). O GDrm mostra tipicamente valores mais altos dos óxidos contidos em minerais ferromagnesianos $(5,77 \%<$ $\mathrm{Fe}_{2} \mathrm{O}_{3}+\mathrm{FeO}+\mathrm{MgO}+\mathrm{TiO}_{2}<12,68 \%$ ) e mais baixos de $\mathrm{Al}_{2} \mathrm{O}_{3}$, quando comparado com os granitóides TTGs arqueanos do Terreno Granito-Greenstone de Rio Maria (Althoff 1996, Leite 2001). Além disso, $\mathrm{Al}_{2} \mathrm{O}_{3}$ varia muito pouco $\left(13,96 \%<\mathrm{Al}_{2} \mathrm{O}_{3}<\right.$ $15,23 \%$ ) em relação à sílica.
Os altos valores de $\mathrm{MgO}$ resultam em valores de \#Mg $(\mathrm{MgO} / \mathrm{MgO}+\mathrm{FeO})_{\text {mol }}$ elevados $(0,48<\# \mathrm{Mg}<0,50)$, quando comparados aos de granitóides cálcico-alcalinos arqueanos. Em diagramas de Harker (Figura 4), nota-se que há um decréscimo marcante nos teores de $\mathrm{Fe}_{2} \mathrm{O}_{3}+\mathrm{FeO}, \mathrm{MgO}$ e $\mathrm{CaO}$ com o incremento de $\mathrm{SiO}_{2}$ nas amostras do granodiorito. $\mathrm{Al}_{2} \mathrm{O}_{3}$ e $\mathrm{Na}_{2} \mathrm{O}$ se mantém estáveis e $\mathrm{K}_{2} \mathrm{O}$ e a razão $\mathrm{K}_{2} \mathrm{O} / \mathrm{Na}_{2} \mathrm{O}$ crescem de forma acentuada paralela à sílica.

Elementos traço $\mathrm{Y}, \mathrm{Zr}$, e $\mathrm{Ba}$ (Figuras $5 \mathrm{c}$, e, f) revelam geralmente pouca variação com o incremento nos valores de sílica, não definindo comportamento compatível ou incompatível. $\mathrm{Rb}$ comporta-se como elemento incompatível (Figura 5a), com seus valores aumentando paralelamente a sílica, ao contrário do $\mathrm{Sr}$ (Figura 5b).

$\mathrm{Yb}$ também apresenta trend de decréscimo nas amostras granodioríticas, embora muito discreto, paralelo ao aumento de $\mathrm{SiO}_{2}$ (Figura 5d), revelando comportamento compatível. A razão $\mathrm{Sr} / \mathrm{Ba}$ varia pouco, havendo, porém, discreto trend de diminuição da razão.

Comportamento dos elementos terras raras Os conteúdos de elementos terras raras do granodiorito (Tabela 2), normalizados em relação ao condrito (Evensen et al. 1978), definem padrões bastante similares, caracterizados pelo enriquecimento acentuado em elementos terras raras leves (ETRL) em relação aos elementos terras raras pesados (ETRP) e forte a moderado fracionamento dos elementos terras raras pesados (Figura 6a), com razões ( $\mathrm{La} / \mathrm{Yb})_{n}$ variando de 15,52 a 44,38 e média de 28,02 (Tabela 2), e anomalias de Eu ausentes ou inexpressivas $\left(0,94<\mathrm{Eu} / \mathrm{Eu}^{*}<1,03\right)$. O fracionamento de minerais, tais como anfibólio, piroxênio e, talvez, granada, poderia explicar o empobrecimento em elementos terras raras pesados.

No diagrama de multi-elementos, normalizado em relação ao manto primitivo (Figura 6b, Taylor \& McLennan 1985), as amostras do GDrm mostram padrões bastante similares, com forte anomalia negativa de $\mathrm{Nb}$ e moderada de $\mathrm{Ti}$ e pequenas anomalias positivas de $\mathrm{Rb}$ e $\mathrm{Ba}$.

CARACTERIZAÇÃO DA SÉRIE MAGMÁTICA O Granodiorito Rio Maria da região de Bannach apresenta $\mathrm{K}_{2} \mathrm{O} / \mathrm{Na}_{2} \mathrm{O}$ $>0,5$, número de $\mathrm{Mg}(\# \mathrm{Mg})$ variando de 0,48 a 0,50, caráter metaluminoso. Segue o trend de séries cálcico-alcalinas em diagramas AFM e K-Na-Ca (Figura 7). Mostra, além disso, enriquecimento relativo em $\mathrm{Ba}, \mathrm{Rb}, \mathrm{Cr}$ e $\mathrm{Ni}$, quando comparado às suítes tonalítica-trondhjemítica-granodioríticas (TTGs) do Terreno Granito Greenstone de Rio Maria (TGGRM) (Althoff 1996, Leite 2001) e de outros terrenos arqueanos do mundo (Martin 1987, Condie 1993).

A hipótese de o Granodiorito Rio Maria ser a fração granodiorítica, mais evoluída da suíte TTG presente no TGGRM foi primeiramente contestada por Medeiros (1987) e Medeiros \& Dall'Agnol (1988) que interpretaram as rochas do GDrm como uma associação cálcico-alcalina, diferenciando-as das típicas associações TTG. Posteriormente, Althoff et al. (1991) e Althoff (1996), quando da comparação entre o GDrm da região de Marajoara com o Tonalito Arco Verde, e Leite (2001), comparando o GDrm da região de Xinguara com o Complexo Tonalítico Caracol e o Trondhjemito Água Fria, reforçaram a maior afinidade do GDrm com as séries cálcico-alcalinas, diferindo portanto das associações TTG. Além das evidências de campo, petrográficas e geoquímicas, a ocorrência das rochas máficas e intermediárias associadas ao GDrm na região de Bannach e a provável cogeneticidade entre elas e o granodiorito dominante na unidade (Oliveira 2005), reforçam a hipótese de não haver ligações genéticas entre o GDrm e as associações TTG. 


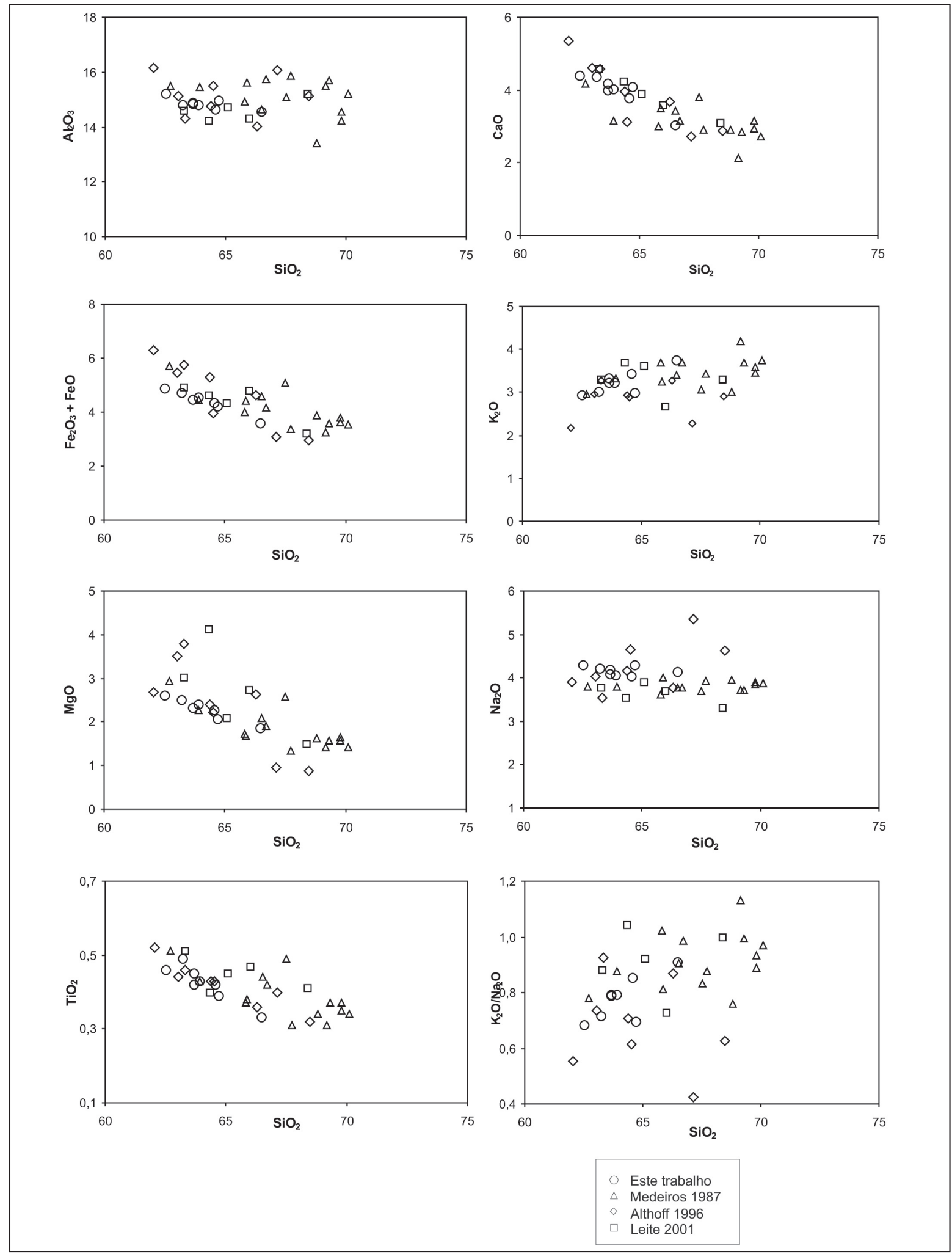

Figura 4-Diagrama de Harker para os óxidos de elementos maiores e menores das amostras do Granodiorito Rio Maria da região de Bannach e demais ocorrências no Terreno Granito-Grrenstone de Rio Maria. SiO em \% em peso.

Por outro lado, similaridades geoquímicas entre rochas do GDrm e granodioritos arqueanos de alto-Mg sanukitóides foram primeiramente aventadas por Althoff et al. (1995) e, posteriormente, reafirmadas por Leite (2001) que, comparando os dados geoquímicos do GDrm da área tipo (Medeiros 1987), região de Marajoara (Althoff 1996) e região de Xinguara (Leite 2001) com aqueles das suítes sanukitóides (Stern et al. 1989, Stern \&
Hanson 1991, Jayananda et al. 1995), observou grandes semelhanças entre estas rochas.

As suítes sanukitóides, definidas por Shirey \& Hanson (1984), Stern et al. (1989) e Stern \& Hanson (1991) na Província Superior no Canadá, são formadas por associação de granitóides com alto-Mg, caracterizada por teores de sílica que variam de 55 a $75 \%$, \#Mg de 0,43 a 0,62, Ni de 7 a 86 ppm, Cr > 100 ppm, Ba 

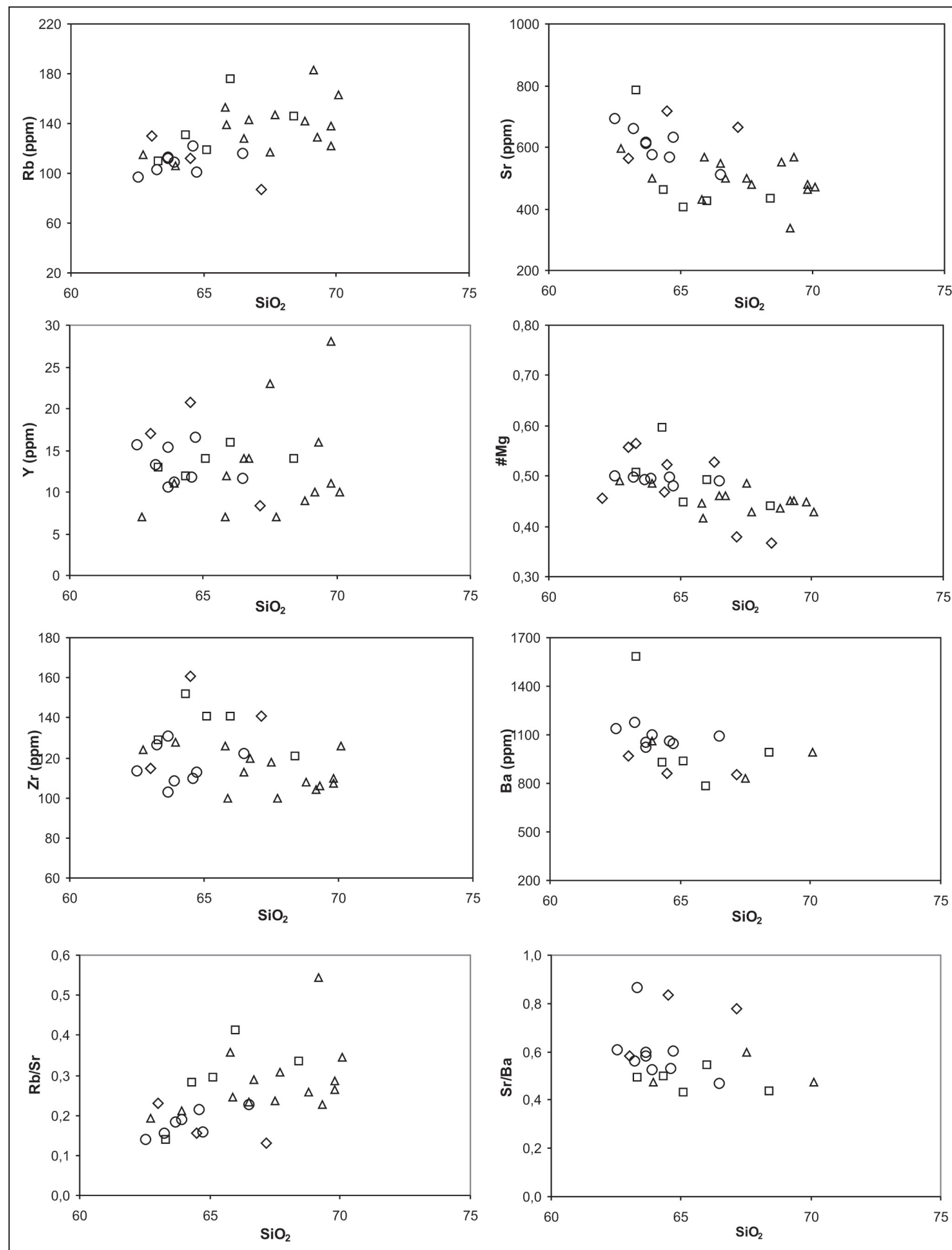

Figura 5 -Diagrama de Harker para os óxidos de elementos traço das amostras do Granodiorito Rio Maria da região de Bannach e demais ocorrências no Terreno Granito-Grrenstone de Rio Maria. $\mathrm{SiO}_{2}$ em \% em peso. Símbolos conforme a Figura 4

e $\mathrm{Sr}$ altos (> $450 \mathrm{ppm}), \mathrm{Rb}$ baixo (28-110 ppm) e razão $\mathrm{Rb} / \mathrm{Sr}$ extremamente baixa. Em termos composicionais correspondem a dioritos a granodioritos enriquecidos em elementos terras raras leves e empobrecidos em terras raras pesados, com anomalia de Eu fraca a ausente. As características geoquímicas do GDrm da região de Bannach são confrontadas àquelas descritas na literatura na Tabela 3. Nela pode-se constatar a semelhança geoquí- mica existente tanto entre o primeiro e as típicas associações sanukitóides, quanto entre as associações presentes nas diversas áreas de ocorrência do GDrm.

A afinidade geoquímica do GDrm com as séries cálcico-alcalinas típicas, sugerida pelos diagramas AFM e K-Na-Ca (Figura 8b, c), é portanto, apenas aparente, pois rochas do GDrm e máficas associadas são bem mais pobres em $\mathrm{CaO}$ e $\mathrm{Al}_{2} \mathrm{O}_{3}$ e mais 


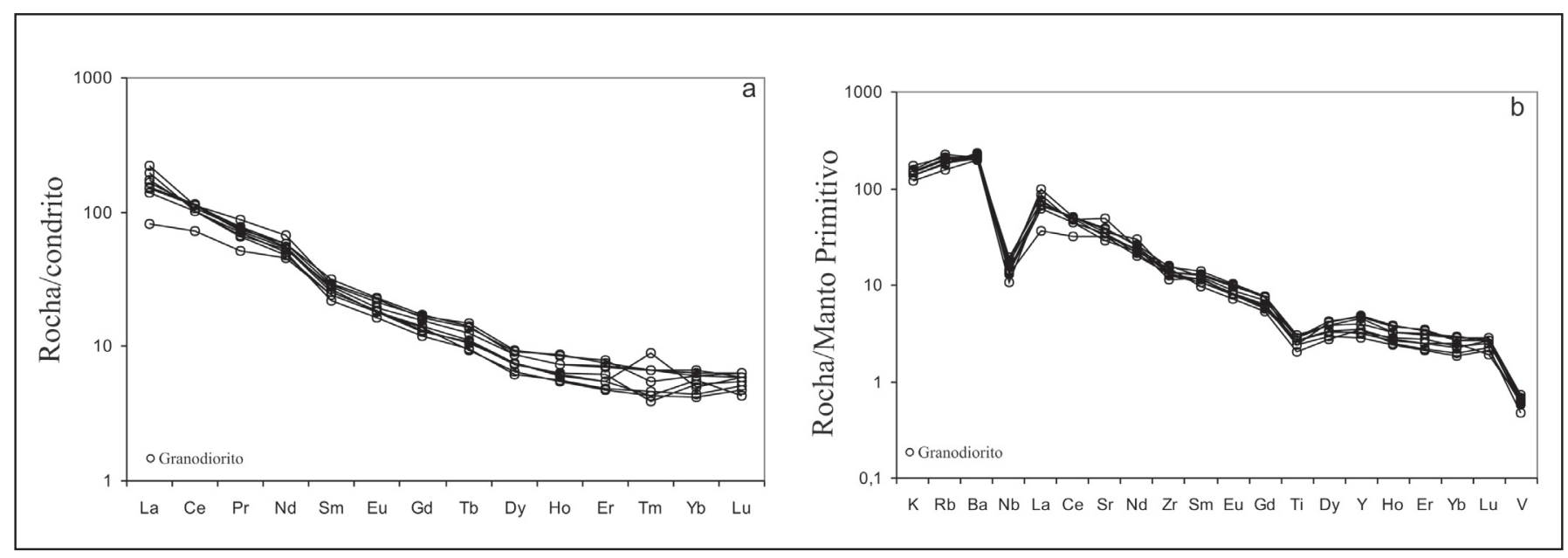

Figura 6 - (a) Padrões de elementos terras raras para as amostras do Granodiorito Rio Maria da região de Bannach. Dados normalizados em relação ao condrito (Evensen et al. 1978); (b) Diagrama multi-elementos para as amostras do Granodiorito Rio Maria da região de Bannach. Dados normalizados em relação ao manto primitivo (Taylor \& McLennan 1985).

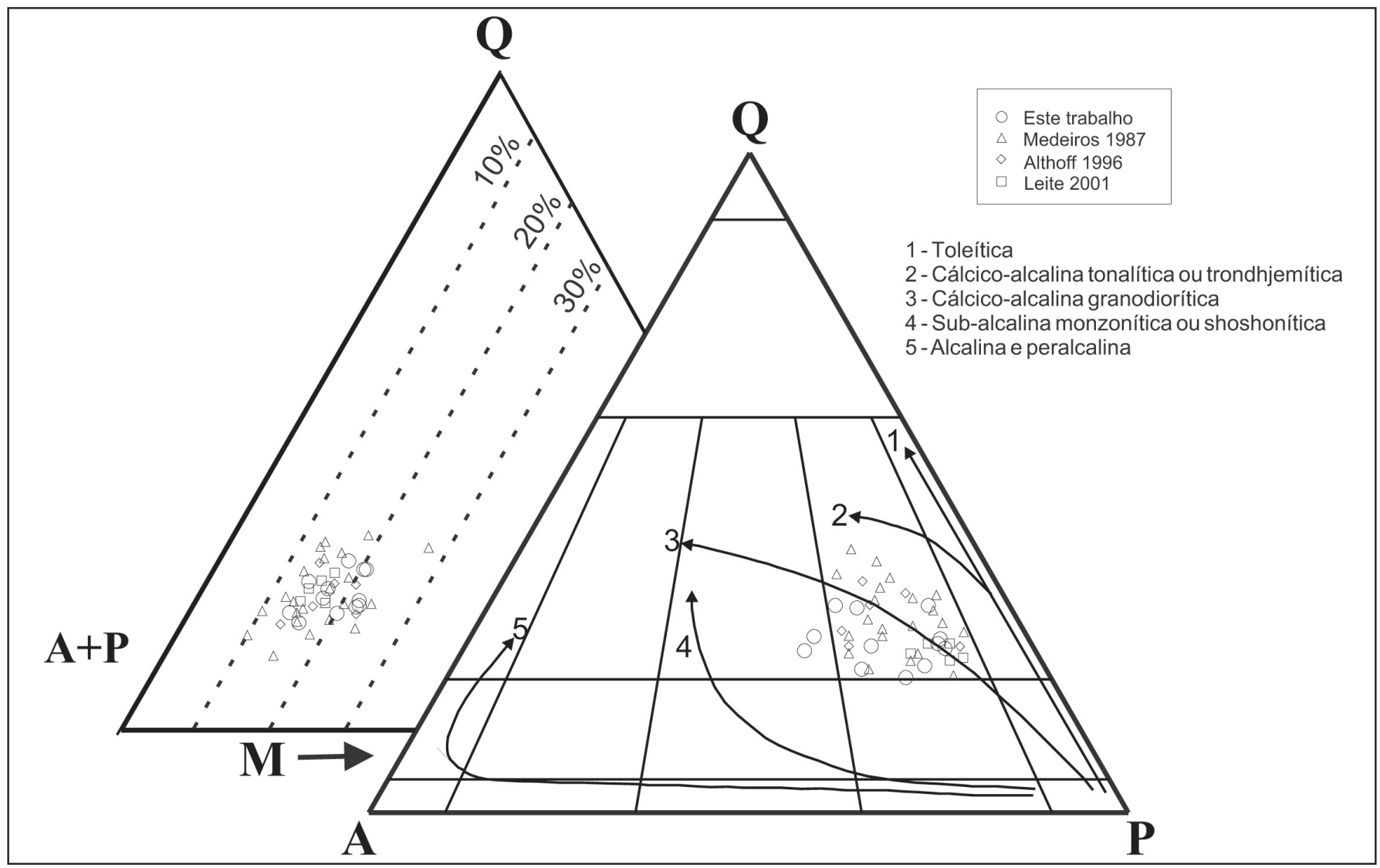

Figura 7-Diagramas Q-A-P e Q-(A+P)-M (Streckeisen 1976) comparativos entre o Granodiorito Rio Maria da região de Bannach (este trabalho) e demais ocorrências no Terreno Granito-Greenstone de Rio Maria (Medeiros 1987, Althoff 1996, Leite 2001).

ricas em $\mathrm{MgO}, \mathrm{Cr}$ e Ni do que aquelas cálcico-alcalinas típicas de margens continentais. Conclui-se que as rochas do GDrm estudadas pertencem às associações sanukitóides, conforme já fora aventado por Althoff (1996) e Leite (2001).

COMPARAÇÃO ENTRE O GRANODIORITO RIO MARIA DA REGIÃO DE BANNACH E SUAS DEMAIS OCORRÊNCIAS NO TGGRM O Granodiorito Rio Maria ocorre em uma grande área do TGGRM, tendo sido estudado por vários autores, sendo importante uma comparação entre as exposições da região de Bannach (Oliveira 2005) e as das demais áreas. Foram escolhidas para esta comparação, feita com base fundamentalmente em dados de campo, petrográficos e geoquímicos, as ocorrências da área-tipo, localizada a sul da cidade de Rio Maria (Medeiros 1987), da região de Vila Marajoara (Althoff 1996), e das proximidades da cidade de Xinguara (Leite 2001).

O Granodiorito Rio Maria da região de Bannach $\left(\right.$ GDrm $\left._{B}\right)$ 
Tabela 3 - Características geoquímicas dos granodioritos ricos em Mg das suites sanukitóides e do Granodiorito Rio Maria (GDrm) em suas diferentes áreas de ocorrência (modificado de Althoff 1996 e Leite 2001). Dados originais : 1 - Stern et al. (1989); 2 - Stern \& Hanson (1991); 3 - Jayananda et al. (1995); 4 -Leite (2001); 5-Althoff (1996); 6-Medeiros (1987); 7 - Medeiros \& Dall'Agnol (1988); * Dados deste trabalho.

\begin{tabular}{|c|c|c|c|c|c|}
\hline & $\begin{array}{c}\text { Granodioritos ricos } \\
\text { em Mg (Sanukitóides) } \\
(1,2,3)\end{array}$ & $\begin{array}{l}\text { GDrm na região de } \\
\text { Bannach }\left(^{*}\right)\end{array}$ & $\begin{array}{l}\text { GDrm na região } \\
\text { de Xinguara (4) }\end{array}$ & $\begin{array}{l}\text { GDrm na região } \\
\text { de Marajoara (5) }\end{array}$ & $\begin{array}{c}\text { GDrm área tipo } \\
(6,7)\end{array}$ \\
\hline $\mathrm{SiO}_{2}(\%)$ & $50-75$ & $58-67$ & $55-68$ & $62-69$ & $62-77$ \\
\hline $\mathrm{Al}_{2} \mathrm{O}_{3}$ & $15-17$ & $14-16$ & $14-15$ & $14-17$ & $13-17$ \\
\hline $\mathrm{K}_{2} \mathrm{O} / \mathrm{Na}_{2} \mathrm{O}$ & $>0,7$ & $0,53-0,91$ & $0,52-1,04$ & 0,76 & 0,9 \\
\hline $\mathbf{P}_{2} \mathbf{O}_{5}$ & $=0,5$ & $<0,2$ & $<0,38$ & $<0,3$ & $<0,2$ \\
\hline$\# \mathbf{M g}$ & $0,43-0,62$ & $0,48-0,60$ & $0,44-0,50$ & 0,52 & 0,48 \\
\hline $\mathrm{Cr}(\mathrm{ppm})$ & $=150$ & $41-308$ & - & $120-135$ & - \\
\hline $\mathbf{N i}$ & $7-86$ & $25-89$ & - & $10-83$ & - \\
\hline $\mathbf{B a}$ & $550-3000$ & $701-1139$ & $739-1586$ & $856-966$ & 832-1061 \\
\hline $\mathbf{R b}$ & $28-110$ & $72-122$ & $67-146$ & $86-130$ & $106-183$ \\
\hline $\mathbf{R b} / \mathrm{Sr}$ & $0,06-0,16$ & $0,09-0,23$ & $0,14-0,34$ & $0,13-0,23$ & $0,2-0,55$ \\
\hline $\mathrm{Ce}_{\mathrm{n}}$ & $64-170$ & $68-114$ & $41-193$ & $101-105$ & - \\
\hline$Y b_{n}$ & $3-6$ & $4-7$ & $1,15-8,47$ & $3,9-8,1$ & - \\
\hline $\mathbf{E u} / \mathbf{E u} *$ & Fraca a ausente & Fraca a ausente & Fraca a ausente & Fraca a ausente & Fraca a ausente \\
\hline Índice de Alumina & Metaluminoso & Metaluminoso & Metaluminoso & Metaluminoso & Metaluminoso \\
\hline
\end{tabular}

Dados originais : 1 - Stern et al. (1989); 2 - Stern \& Hanson (1991); 3 - Jayananda et al. (1995); 4 - Leite (2001); 5 - Althoff (1996); 6 Medeiros (1987); 7 - Medeiros \& Dall’Agnol (1988); * Dados deste trabalho.

não difere em termos de composição modal de forma acentuada das demais ocorrências (GDrm ${ }_{\mathrm{D}}$ ) mencionadas (Figura 9). Apresenta composições essencialmente granodioríticas, as quais se sobrepõem em boa parte àquelas observadas no GDrm $_{D}$ (Figura $8)$. Ocorrem algumas diferenças sutis como as variações monzograníticas pouco expressivas do GDrm ${ }_{\mathrm{B}}$, bem como granodioritos mais ricos em quartzo que ocorrem principalmente na área-tipo (Medeiros 1987) e outras, mais importantes, como a presença expressiva de rochas de composição quartzo-diorítica e quartzo-monzodiorítica e máficas acamadadas apenas na região de Bannach.

Em termos geoquímicos, quando plotadas em diagramas de Harker (Figuras 4 e 5), há uma tendência à superposição entre os campos definidos pelas amostras das diversas áreas de ocorrência e os trends de evolução com a sílica são similares. Constata-se, ainda, que algumas amostras do GDrm da área-tipo mostram-se relativamente mais evoluídas que as das demais áreas, apresentando-se mais ricas em $\mathrm{SiO}_{2}, \mathrm{Al}_{2} \mathrm{O}_{3} \mathrm{~K}_{2} \mathrm{O}$ e $\mathrm{Rb}$ e mais pobres em $\mathrm{Fe}_{2} \mathrm{O}_{3}+\mathrm{FeO}, \mathrm{CaO}, \mathrm{MgO}, \mathrm{TiO}_{2}$, além de exibirem valores mais baixos de $\mathrm{AMg}$.

No que diz respeito às demais características geoquímicas, o GDrm das diferentes áreas apresenta caráter metaluminoso (Figura 8d) e no diagrama normativo Ab-An-Or (O’Connor 1965, modificado por Barker 1979) (Figura 8a) plota fundamentalmente no campo dos granodioritos. No diagrama $\mathrm{Ab}-\mathrm{An}$-Or as rochas do GDrm $_{\mathrm{D}}$ plotam um pouco acima do $\mathrm{GDrm}_{\mathrm{B}}$, refletindo seus teores de $\mathrm{Al}_{2} \mathrm{O}_{3}$ ligeiramente mais elevados, levando a aumento do componente normativo An quando do cálculo da norma.

No triângulo AFM (Figura 8b) as amostras do GDrm D $_{\text {plo- }}$ tam no campo das séries cálcico-alcalinas, conforme definido por Irvine \& Baragar (1971), sobrepondo-se às amostras granodioríticas do $\mathrm{GDrm}_{\mathrm{B}}$. No diagrama K-Na-Ca (Figura 8c) as amostras do GDrm D sobrepõem-se às rochas granodioríticas do GDrm $_{\mathrm{B}}$, alinhando-se segundo o trend cálcico-alcalino (Nockolds \& Allen 1953).

Em relação aos padrões de elementos terras raras, foram comparados os do Granodiorito Rio Maria da região de Bannach (este trabalho) com os da região de Xinguara (Leite 2001), sendo observada grande similaridade (Figura 9), sendo marcantes o enriquecimento acentuado em ETRL em relação aos ETRP, com forte a moderado fracionamento dos ETRP e fraca a ausente anomalia de Eu.

Com base nos dados acima, observa-se que, conforme esperado, o Granodiorito Rio Maria da região de Bannach e das demais áreas estudadas no TGGRM mostram notáveis semelhanças petrográficas e geoquímicas, e, ao que tudo indica, idade coincidente. Portanto as diversas ocorrências do GDrm discutidas podem ser enquadradas em uma suíte magmática.

CONCLUSÕES (1) Na região de Bannach, o Granodiorito Rio Maria $\left(\mathrm{GDrm}_{\mathrm{B}}\right)$ é intrusivo nas seqüências supracrustais do Supergrupo Andorinhas; seu posicionamento estratigráfico em relação aos tonalitos-trondhjemitos do tipo Mogno não foi definido, admitindo-se que tenham idades similares; é intrudido por leucogranitos correlacionados ao Granito Xinguara e pelos granitos paleoproterozóicos Musa e Bannach.;

(2) As composições modais das rochas do GDrm ${ }_{B}$ alinhamse segundo o trend da série cálcico-alcalina granodiorítica de Lameyre \& Bowden (1982) com modificações de Bowden et al. (1984). O GDrm B possui, além de composições granodioríticas que são amplamente dominantes nesta unidade, composições monzograníticas bastante subordinadas. Os enclaves máficos que ocorrem no GDrm são essencialmente dioritos e, subordinadamente, monzodioritos; 
(3) Os tipos texturais de epidoto denominados $\mathrm{Ep}^{1}$ e $\mathrm{Ep}^{2}$, identificados como fases acessórias no GDrm, mostram características texturais de epidoto magmático. A presença constante de anfibólio como máfico dominante e a preservação de epidoto magmático nestas rochas, aliadas às características petrográficas, sugerem condições bastante hidratadas para o magma formador do GDrm;

(4) As amostras do GDrm $\mathrm{B}$ apresentam caráter metaluminoso. Plotam no campo dos granodioritos no diagrama Ab-An-Or mostrando comportamento diferente dos granitóides TTG típicos, o que se confirma no diagrama $\mathrm{K}-\mathrm{Na}-\mathrm{Ca}$, onde o $\mathrm{GDrm}_{\mathrm{B}}$ foge do trend trondhjemítico, mostrando enriquecimento em $\mathrm{K}$ em relação aos granitóides TTG e alinhamento segundo o trend das séries cálcico-alcalinas. Entretanto, o $\mathrm{GDrm}_{\mathrm{B}}$ mostra conteúdos mais baixos de $\mathrm{Al}_{2} \mathrm{O}_{3}$ e $\mathrm{CaO}$ e mais altos de $\mathrm{MgO}, \mathrm{Cr}$ e $\mathrm{Ni}$ do que as séries cálcico-alcalinas, assemelhando-se geoquimicamente aos granodioritos arqueanos ricos em Mg das suítes sanukitóides da Província Superior do Canadá (Stern et al. 1989, Stern \& Hanson 1991) e do Cráton Dharwar da Índia (Jayananda et al. 1995, Moyen et al. 2003). Conclui-se que o Granodiorito Rio Maria e rochas associadas correspondem a uma série sanukitóide e não a uma verdadeira série cálcico-alcalina;

(5) Os conteúdos e padrões de elementos terras raras das rochas estudadas mostram enriquecimento acentuado em elementos terras raras leves (ETRL) em relação aos elementos terras raras pesados (ETRP), indicando forte a moderado fracionamento

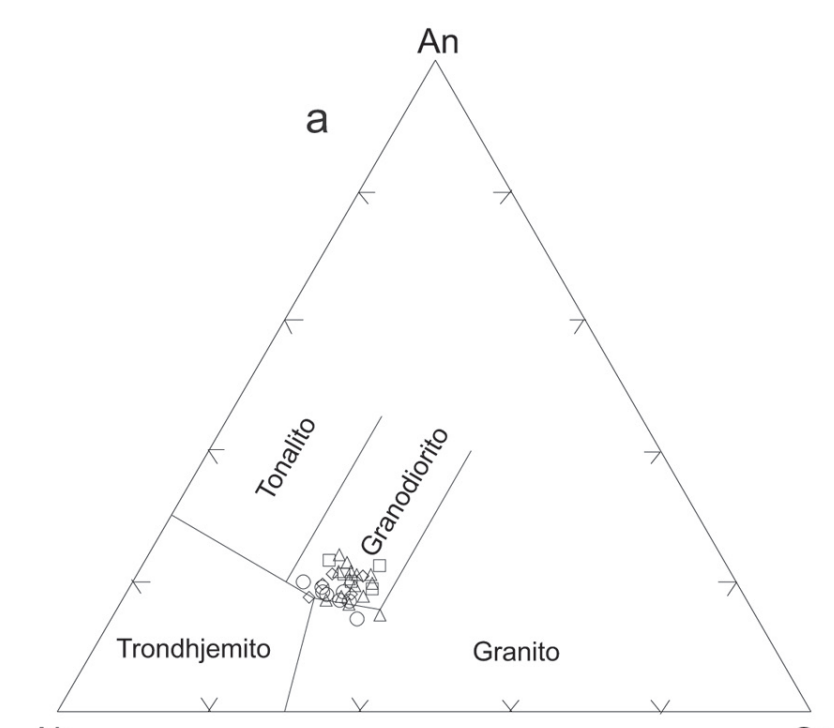

$\mathrm{Ab}$
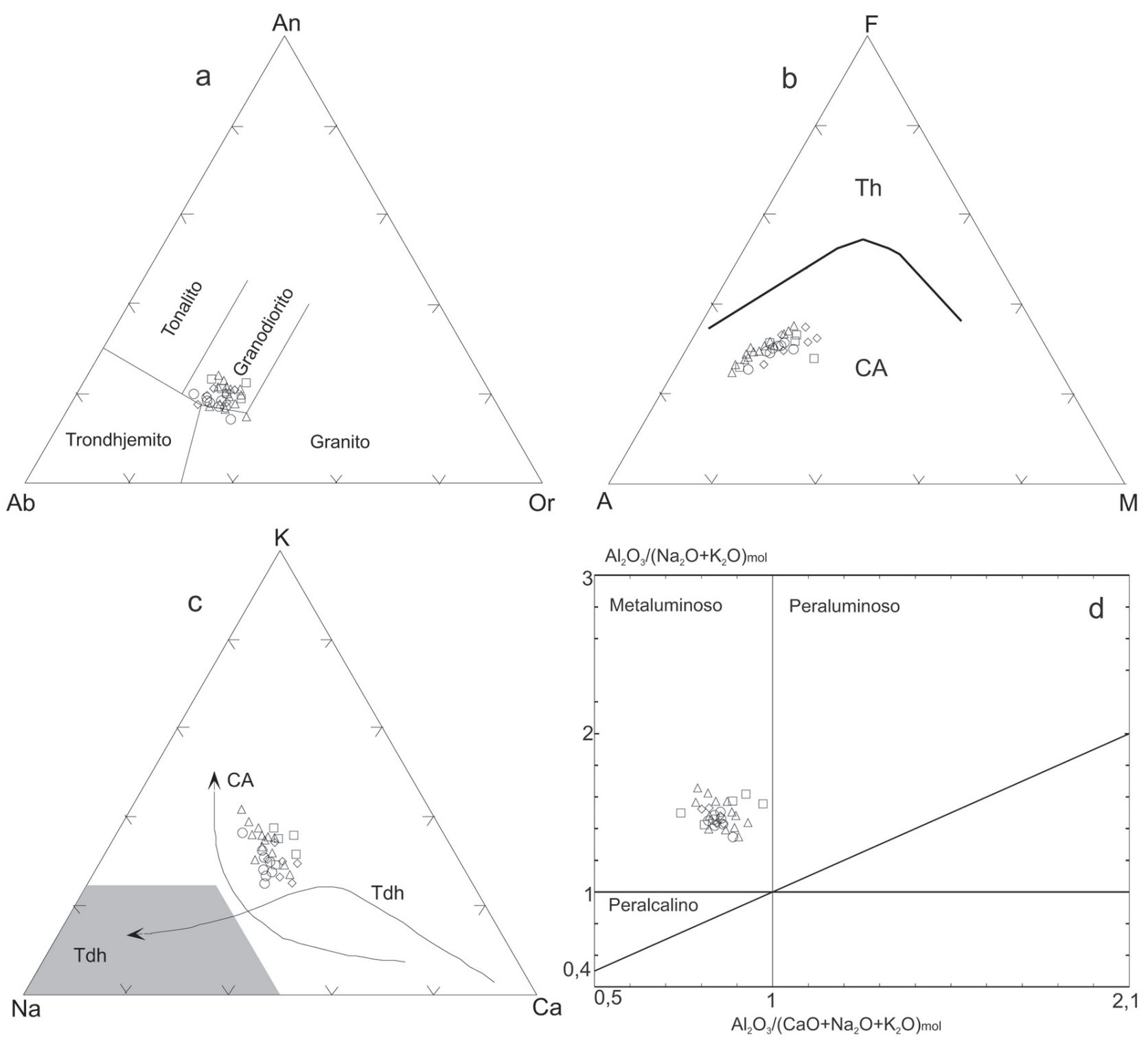

Figura 8 - Caracterização geoquímica do Granodiorito Rio Maria da região de Bannach e demais ocorrências no Terreno Granito-Greenstone de Rio Maria. SiO em \% em peso. (a) Diagrama An-Ab-Or normativo (O'Connor 1965, com campos de Barker 1979). As amostras do GDrm concentram-se no campo dos granodioritos, com raras amostras no campo dos granitos; (b) Diagrama AFM $\left(\mathrm{A}=\mathrm{Na} \mathrm{O}_{2}+\mathrm{K}_{2} \mathrm{O} ; \mathrm{F}=\mathrm{FeO}+0,9 * \mathrm{Fe}_{2} \mathrm{O}_{3} ; \mathrm{M}=\mathrm{MgO}\right)$ mostrando que as rochas estudadas incidem no campo cálcicoalcalino. Os campos são de Irvine \& Baragar (1971). Th = toleitos, CA = cálcico-alcalino; (c) Diagrama K-Na-Ca mostrando que as rochas estudadas neste trabalho alinham-se ao trend cálcico-alcalino (CA) de Nockolds \& Allen (1953); trend e campo trondhjemítico (Tdh) segundo Barker \& Arth (1976); (d) Diagrama $\mathrm{Al}_{2} \mathrm{O}_{3} /\left(\mathrm{CaO}+\mathrm{Na} \mathrm{O}_{2} \mathrm{~K}_{2} \mathrm{O}\right)$ mol, mostrando o caráter metaluminoso do GDrm. Símbolos conforme a Figura 4. 


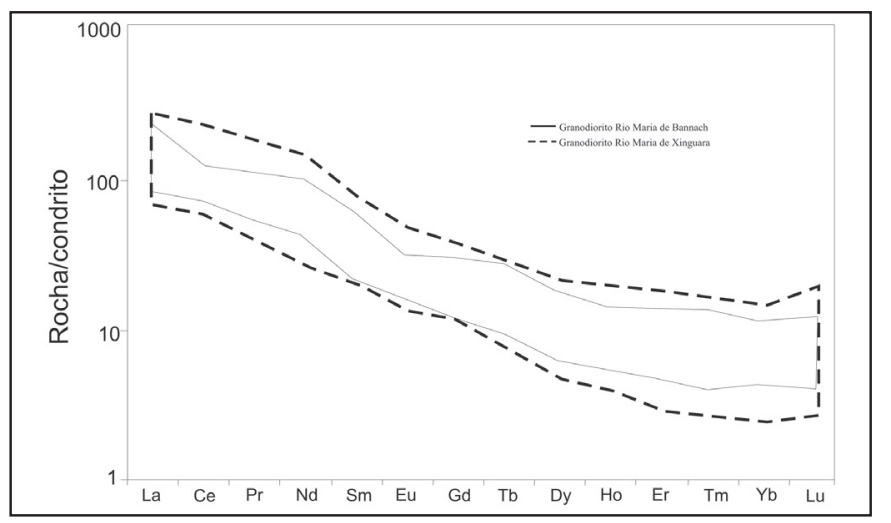

Figura 9-Padrões de elementos terras raras das amostras do Granodiorito Rio Maria da região de Bannach (linha contínua; este trabalho) e da região de Xinguara (linha tracejada; Leite 2001). Os dados foram normalizados em relação ao condrito (Evensen et al. 1978). dos ETRP;

(7) As rochas do GDrm ${ }_{B}$ são similares, em termos petrográficos e geoquímicos, àquelas das demais ocorrências do GDrm no Terreno Granito-Greenstone de Rio Maria, podendo as diversas ocorrências já estudadas ser agrupadas em uma mesma suíte magmática.

Agradecimentos Aos pesquisadores do Grupo de Pesquisa Petrologia de Granitóides (GPPG-CG-UFPA) pelo apoio nas diversas etapas deste trabalho. Ao CNPq pela concessão da bolsa de mestrado do primeiro autor e ao Centro de Geociências (CGUFPA) pelo suporte técnico. Este artigo é uma contribuição para os projetos Pronex (Projeto 103/98 - Processo 66.2103/1998-0, "Magmatismo, evolução crustal e metalogênese da Província Mineral de Carajás") e CNPq (nº 55.0739/01-7, 476075/03-3, "Magmatismo da Província Central e Mineralizações Associadas”).

\section{Referências}

Almeida J.A.C. 2005. Geologia, petrografia e geoquimica do Granito Anorogênico Bannach, terreno granito- "greenstone" de Rio Maria-Pará. Dissertação de Mestrado, Universidade Federal do Pará.

Althoff F.J. 1996. Étude pétrologique et structurale des granitoïdes de Marajoara (Pará, Brésil): leur rôle dans l'évolution archéenne du craton Amazonien (2,7-3,2 Ga). Tese de Doutoramento, Université Henri Poincaré, Nancy I - France. 296p.

Althoff F.J., Barbey P., Boullier A.M. 2000. 2.8-3.0 Ga plutonism and deformation in the SE Amazonian craton: the Archean granitoids of Marajoara (Carajás Mineral province, Brazil). Precambrian Research, 104:187-206.

Althoff F.J., Barbey P., Boullier A.M., Dall'Agnol, R. 1995. Composição e estrutura dos granitóides arqueanos da região de Marajoara. Boletim do Museu Paraense Emílio Goeldi - Série Ciências da Terra, 7:5-26.

Althoff F.J., Dall'Agnol R., Souza Z.S. 1991. Região de Marajoara - SE do Pará: prolongamento dos terrenos arqueanos de Rio Maria ou retrabalhamento? In: SBG, Simpósio de Geologia da Amazônia, 3 , Belém, Anais p. 130-141.

Barker F. 1979. Trondhjemites: definition, environment and hypotheses of origin. In: F. Barker, (Ed.) Trondhjemites, dacites and related rocks. Amsterdam, Elsevier. pp.: 1-12.

Barker F. \& Arth J.G. 1976. Generation of trondhjemitic-tonalitic liquids and Archaean bimodal trondhjemite-basalt suites. Geology, 4:596-600.

Bowden P., Batchelor R.A., Chapell B.W., Didier J., Lameyre J. 1984. Petrological, geochemical and source criteria for the classification of granitic rocks: a discussion. Physics. Earth Planet Sciences, 35:1-11.

Condie K.C. 1993. Chemical composition and evolution of the upper continental crust: Contrasting results from surface sample and shales. Chemical Geology, 104:1-37.

Condie K.C. \& Hunter D.R. 1976. Trace elements geochemistry of Archean granitic rocks from Barberton region, South Africa. Earth and Planetary Science Letters, 29:389-400.

CPRM 2000. Xinguara, Folha SB.22-Z-C. Estado do Pará. Escala 1:250.000. Brasília. Programa Levantamentos Geológicos Básicos do Brasil.

Dall'agnol R., Teixeira N.P., Rämo O.T., Moura C.A.V., Macambira M.J.B., Oliveira D.C. 2005. Petrogenesis of the Paleoproterozoic rapakivi A-type granites of the Archean Carajás metallogenic province, Brazil. Lithos, 80: 101-129.

Dall'Agnol R., Souza Z.S., Althoff F.J., Barros C.E.M., Leite A.A.S., Jorge João X. S. 1997. General aspects of the granitogenesis of the Carajás metallogenic province. In: Recursos Minerais-SGRM,
International Symposium on Granites and Associated Mineralizations, 2. Salvador, Excursions Guide, p.135-161.

DOCEGEO. 1982. Relatório final de pesquisa, área Pedra Preta. Belém. $3 \mathrm{v}$.

DOCEGEO 1988. Revisão litoestratigráfica da Província Mineral de Carajás. In: SBG, Congresso Brasileiro de Geologia, 35, Belém, Anais, p. 11-54.

Duarte K. D. 1992. Geologia e geoquímica do Granito Mata Surrão ( $S W$ de Rio Maria - Pa): um exemplo de granito "stricto sensu" Arqueano. Dissertação de Mestrado, Centro de Geociências, Universidade Federal do Pará, Belém, 217p.

Evensen N.M., Hamilton P.T., O’Nions R.K. 1978. Rare earth abundances in chondritic meteorites. Geochemical of Cosmochemical Acta, 39:55.64.

Huhn S.R.B., Santos A.B.S., Amaral A.F., Ledsham E.J., Gouveia J. L., Martins L.B.P., Montalvão R.M.G., Costa V.G. 1988. O terreno granito-greenstone da região de Rio Maria - Sul do Pará. In: SBG, Congresso Brasileiro de Geologia, 35, Belém, Anais. v. 3, p. 14381453.

Irvine T.N. \& Baragar W.R.A. 1971. A guide to the chemical classification of the common volcanic rocks. Canadian Journal of the Earth Science, 8:523-547.

Jayananda M., Martin H., Peucat J.J., Mahabaleswar B. 1995. Late Archaean crust-mantle interactions: geochemistry of LREE-enriched mantle derived magmas. Example of the Closopet batholith, southern India. Contributions Mineralogy and Petrology, 119:314329.

Lameyre J. \& Bowden P. 1982. Plutonic rock type series: discrimination of various granitoid series and related rocks. Journal of Volcanology and Geothermal Research, 14: 169-186.

Le Maitre R. W. 2002. A classification of igneous rocks and glossary of terms. 2nd Edition, London, 193 p.

Leite A.A.S., Dall'Agnol, R., Macambira, M. J. B., Althoff, F. J. 2004. Geologia e geocronologia dos granitóides arqueanos da região de Xinguara (PA) e suas implicações na evolução do Terreno Granito-Greenstone de Rio Maria. Revista Brasileira de Geociências. 34:447-458

Leite A.A.S. 2001. Geoquímica, petrogênese e evolução estrutural dos granitóides arqueanos da região de Xinguara, SE do Cráton Amazônico. Tese de Doutorado, Centro de Geociências, Universidade Federal do Pará, Belém, 330p.

Macambira M.J.B. 1992. Chronologie U/Pb, Rb/Sr, K/Ar et croissance de la croûte continentale dans L'Amazonie du sud-est; exemple de la région de Rio Maria, Province de Carajas, Brésil. Tese de Doutorado, Université Montpellier II-France Montpellier, 212 p. 
Macambira M.J.B. \& Lafon J.M. 1995. Geocronologia da Província Mineral de Carajás: Síntese dos dados e novos desafios. Boletim do Museu Paraense Emílio Goeldi, Série Ciências da Terra, 7:263287.

Martin H. 1987. Petrogenesis of Archaean trondhjemites, tonalities and granodiorites from eastern Finland: major and trace element geochemistry. Journal of Petrology, 28:921-953.

Medeiros H. 1987. Petrologia da porção leste do maciço granodiorítico Rio Maria, Sudeste do Pará. Dissertação de Mestrado, Centro de Geociências, UFPA, Belém, 166p.

Medeiros H., \& Dall'Agnol R. 1988. Petrologia da porção leste do Batólito Granodiorítico Rio Maria, sudeste do Pará. In: SBG, Congresso Brasileiro de Geologia, 35, Belém, Anais, v. 3, p.1488-1499.

Moyen J. F., Martin H., Jayananda M., Auvray B. 2003. Late-Archaean granites: a typology based on the Dharwar Craton (India). Precambrian Research, 2375:1-21.

Nockolds S. R. \& Allen R. 1953. The geochemistry of some igneous rocks series. Geochimica et Cosmochimica Acta, 4:105-142.

O'Connor J.T. 1965. A classification for quartz-rich igneous rocks based on feldspar ratios. US Geological Survey Profissional Papers, 525B: 79-84.

Oliveira M. A. 2005. Geologia, petrografia e geoquímica do Granodiorito Sanukitóide Arqueano Rio Maria e rochas máficas associadas, leste de Bannach-PA. Dissertação de Mestrado, Universidade Federal do Pará, 151p.

Pimentel M.M. \& Machado N. 1994. Geocronologia U-Pb dos Terrenos granito-greenstone de Rio Maria, Pará. In: SBG, Congresso Brasileiro de Geologia, 38, Camboriú, Boletim de Resumos Expandidos, p. 390-391.

Ringwood A. E. 1975. Composition and Petrology os the earth's mantle. MacGraw-Hill Editor, 618p.

Rolando A.P. \& Macambira M.J.B. 2003. Archean crust formation in Inajá range area, SSE of Amazonian Craton, Brazil, basead on zircon ages and Nd isotopes. In: South American Symposium on Iso- tope Geology, 4, Salvador. Expanded Abstracts, CD-ROM.

Shand S.J. 1950. Eruptive rocks their genesis, composition, classification e their relation to ore deposit. 4ed., London, 488p.

Shirey S.B.; Hanson, G.N. 1984. Mantle-derived Archean monzodiorites e trachyandesites. Nature, 310:222-224.

Sial A.N. 1990. Epidote-bearing calc-alkalic granitoids in northeast Brazil. Revista Brasileira de Geociências, 20:88-100.

Souza Z.S. 1994. Geologia e petrogênese do "greenstone belt" identidade: implicações sobre a evolução geodinâmica do terreno granito- "greenstone" de Rio Maria, SE do Pará. Tese de Doutorado, Universidade Federal do Pará, v.1 e 2, 624p.

Souza Z.S., Medeiros H., Althoff F.J., Dall'Agnol R. 1990. Geologia do terreno granito greenstone Arqueano da região de Rio Maria, sudeste do Pará. In: SBG, Congresso Brasileiro de Geologia, 36, Natal, Anais, v. 6, p. 2913-2928.

Souza Z.S., Santos A B., Ledsham E.J., Martins L.P.B., Huhn S.B., Costa V.G. 1988. Feições geológicas e estruturais do greenstone belt de Identidade, região de Xinguara - Rio Maria, sul do Pará. In: SBG, Congresso Brasileiro de Geologia, 35, Belém, Anais, v. 3, p. 1453-1467.

Stern A.L. \& Hanson G. 1991. Archean high-Mg granodiorite: a derivate of light rare earth element-enriched monzodiorite of mantle origin. Journal of Petrology, 32: 201-238.

Stern A.L., Hanson G., Shirey S.B. 1989. Petrogenesis of mantle-derived, LILE-enriched Archean monzodiorites and trachyandesites (sanukitoids) in southwestern Superior Province. Canadian Journal of Eath Sciences, 26:1688-1712.

Streckeisen A.L. 1976. To each plutonic rock its proper name. Earth Science Review, 12:1-33.

Taylor S.R. \& Mclennan S.M. 1985. The continental crust: Its composition and evolution. Backwell Scientific, Oxford, 321p.

Manuscrito A-1618 Revisão aceita em 25 de julho de 2006 